\title{
Information Privacy, Cultural Values, and Regulatory Preferences
}

\author{
John H. Benamati, Miami University, USA \\ Zafer Ozdemir, Miami University, USA \\ H. Jeff Smith, Miami University, USA
}

\begin{abstract}
The global nature of e-commerce is complicating privacy issues because perceptions of privacy, trust, risk, and fair information practices vary across cultures, and differences in national regulation create challenges for global information management strategies. Despite the spike in international regulatory attention devoted to privacy issues and the tensions associated with them, there has been very little research on the relationship between information privacy concerns and consumers' regulatory preferences, and even rarer is research that incorporates cultural values into a framework that includes privacy concerns and regulation. This study examines privacy concerns, a full complement of cultural values, trust, risk, and regulation at the individual level in a cohesive manner. Relying on a dataset of consumers gathered in the United States and India, the authors test a model that incorporates these constructs as well as trust and risk beliefs. The model explains $48 \%$ of the variance in consumers' regulatory preferences, and all but one of the hypotheses find statistical support.
\end{abstract}

\section{KEYWORDS}

Cultural Values, Information Privacy, Regulatory Preferences

\section{INTRODUCTION}

In a world with unlimited potential for gathering, storing, processing, disseminating, and exploiting personal information, consumers are inevitably concerned about their privacy, and some are losing hope altogether. A new survey revealed that the percentage of adults who agree with the statement "online privacy is possible" have dropped substantially from 61\% in 2018 to 32\% in 2019 (Sterling, 2019). The survey also reported that the recent privacy scandals led $78 \%$ of the respondents to modify their online behavior, with $74 \%$ of them reporting sharing less information online. Those who have not changed their behavior, for the most part, either had accepted a lack of privacy when engaging online or were already highly protective of their information.

Extensive research on information privacy concerns has concluded that a substantial segment of the society will resist certain online transactions or technologies, thereby limiting the growth of the digital economy, due to significant and growing privacy concerns (Adjerid, Peer, \& Acquisti, 2018; Angst \& Agarwal, 2009; Bansal, Zahedi, \& Gefen, 2010; Buckman, Bockstedt, \& Hashim, 2019; Dinev et al., 2006; Dinev, Hart, \& Mullen, 2008; Malhotra, Kim, \& Agarwal, 2004; Son \& Kim, 2008; H. Xu, Teo, Tan, \& Agarwal, 2012). A variety of surveys and experiments have also shown that privacy concerns impede electronic commerce (Buckman et al., 2019; Hoffman, Novak, \& Peralta,

\section{DOI: 10.4018/JGIM.2021050106}

This article, published as an Open Access article on April 16, 2021 in the gold Open Access journal, Journal of Global Information Management (JGIM) (converted to gold Open Access on January 1, 2021), is distributed under the terms of the Creative Commons Attribution 
1999; International, 2005; Smith, Milberg, \& Burke, 1996; Tang, Hu, \& Smith, 2008; Westin, 2004) and undermine the trust between businesses and consumers (Hoffman et al., 1999; Tang et al., 2008).

The global nature of the Internet and e-commerce is making privacy issues even more complex because the perceptions of privacy, trust in online companies, risk of disclosing information online, and fair information practices vary across cultures (Bellman, Johnson, Kobrin, \& Lohse, 2004; Cao \& Everard, 2008; Dinev et al., 2006; Milberg, Burke, Smith, \& Kallman, 1995; Milberg, Smith, \& Burke, 2000). For example, "in Europe, privacy is viewed as a 'human rights' issue; in the U.S., it is more often seen as a matter for contractual negotiation" (Smith, 2001, p.13). The European Union's General Data Protection Regulation (GDPR) that went into effect in May of 2018 further illustrates this (Greengard, 2018). In 1964 India's supreme court acknowledged the right of privacy as implicit in their constitution although India lacks regulation similar to GDPR (Basu, 2010). In the United States, privacy can be exchanged for personalized services or other benefits, and such differences in practice greatly affect how privacy is perceived by individuals and regulated by governments (Smith, 2001; Tang et al., 2008). Additionally, differences in cultural values have become important as the Internet has enabled massive amounts of consumer data to be transferred instantly across national borders (Nijhawan, 2003). Therefore, understanding and addressing the variations in trust and privacy perceptions across various cultures has become imperative for global corporate managers (Dinev et al., 2006).

While the Internet greatly facilitates the flow of information about consumers, differences in national regulation create challenges for global information management strategies, sometimes limiting or even preventing the free flow of valuable information (Fjetland, 2002). Governments around the world have struggled with regulating issues associated with information privacy, and their approaches have differed greatly (Flaherty, 1989; Milberg et al., 2000; Smith, 2001). A common thread in press reports is that varying regulatory approaches to cross-border data flows are causing great consternation among firms that compete internationally (Kanter, 2014; Miltgen \& Smith, 2015; Singer, 2013). Thus, careful consideration of variations in national regulations of information privacy is another imperative for today's corporate managers.

Despite the spike in international regulatory attention devoted to privacy issues and the tensions associated with them, there has been very little research on the relationship between information privacy concerns and consumers' regulatory preferences defined as an individual's preferences regarding the degree of regulatory control to enforce user control of privacy in his or her country (Miltgen \& Smith, 2015). Even rarer is research that incorporates cultural values into a framework that includes privacy concerns and regulation. Additionally, because trust and risk beliefs have been identified in the privacy research stream as being especially salient in individuals' privacy-related decisions (Smith, Dinev, \& Xu, 2011), we argue that those constructs are important in such research models. To the best of our knowledge, there is no prior study that examines privacy concerns, a full complement of cultural values, trust, risk, and regulation at the individual level in a cohesive manner, despite the inherent relationships among these constructs (see Table 1). This study aims to fill this gap in the literature.

Almost all of the studies that have addressed the relationship between privacy concerns and cultural values have relied on some of the original four cultural dimensions that were identified by Hofstede (): specifically, individualism-collectivism (IND), power distance (PDI), uncertainty avoidance (UAI), and masculinity-femininity (MAS). However, most of these studies used only a subset of the cultural dimensions, and none of them included the dimension of long-term orientation (LTO), which Hofstede documented in his later work (). Recently, a large group of social scientists and management scholars undertook the long-term GLOBE project that focuses on culture and leadership in 61 countries and aims to broaden the scope of inquiry regarding the relationship between culture and leadership. A couple of the studies we identified employ GLOBE project's cultural dimensions, which build largely on Hofstede's dimensions. In particular, Cho et al. (2009) use four dimensions 
Table 1. Previous studies with a focus on information privacy concerns, culture, and regulation ${ }^{1}$

\begin{tabular}{|c|c|c|c|c|}
\hline Study & $\begin{array}{c}\text { Privacy } \\
\text { Concerns }^{2}\end{array}$ & Cultural Values $^{3}$ & Trust/risk & Regulation \\
\hline Bellman et al. (2004) & Consequent & $\begin{array}{l}\text { Antecedent (Country level } \\
\text { (PDI, IND, UAI, MAS) }\end{array}$ & N/A & $\begin{array}{l}\text { Antecedent (Country level) } \\
\text { Consequent (Individual level) }\end{array}$ \\
\hline $\begin{array}{l}\text { Cao and Everard } \\
(2008)\end{array}$ & Mediator & $\begin{array}{l}\text { Antecedent (Individual level) } \\
\text { (PDI, IND, UAI) }\end{array}$ & N/A & N/A \\
\hline Cho et al. (2009) & Mediator & $\begin{array}{l}\text { Antecedent (Country level) } \\
\text { (IND, UAI) }\end{array}$ & N/A & N/A \\
\hline $\begin{array}{l}\text { Cockroft and Rekker } \\
\text { (2015) }\end{array}$ & N/A & $\begin{array}{c}\text { Antecedent (Country level) } \\
\text { (GLOBE dimensions) }\end{array}$ & N/A & Consequent (Country level) \\
\hline $\begin{array}{l}\text { Cockroft et al. } \\
\text { (2009) }\end{array}$ & N/A & $\begin{array}{l}\text { Antecedent (Country level) } \\
\text { (GLOBE dimensions) }\end{array}$ & N/A & Consequent (Country level) \\
\hline Dinev et al. (2006) & Mediator & $\begin{array}{l}\text { Moderator (Country level) } \\
\text { (No dimensions) }\end{array}$ & Trust & N/A \\
\hline James et al. (2017) & Antecedent & $\begin{array}{l}\text { Antecedent (Individual level) } \\
\text { (INDI) }\end{array}$ & Risk & N/A \\
\hline $\begin{array}{l}\text { Krasnova et al. } \\
\qquad(2012)\end{array}$ & Antecedent & $\begin{array}{l}\text { Moderator (Individual level) } \\
\text { (IND, UAI) }\end{array}$ & Trust & N/A \\
\hline Lowry et al. (2011) & Mediator & $\begin{array}{l}\text { Antecedent (Individual level) } \\
\text { (PDI, IND, UAI, MAS) }\end{array}$ & N/A & N/A \\
\hline Lwin et al. (2007) & Mediator & N/A & N/A & Antecedent (Individual level) \\
\hline Milberg et al. (1995) & Mediator & $\begin{array}{l}\text { Antecedent (Country level) } \\
\text { (PDI, IND, UAI) }\end{array}$ & N/A & Consequent (Country level) \\
\hline Milberg et al. (2000) & Mediator & $\begin{array}{l}\text { Antecedent (Country level) } \\
\text { (PDI, IND, UAI, MAS) }\end{array}$ & N/A & $\begin{array}{c}\text { Mediator (Country level) } \\
\text { Consequent (Individual level) }\end{array}$ \\
\hline $\begin{array}{l}\text { Miltgen and Smith } \\
\qquad(2015)\end{array}$ & Mediator $^{4}$ & N/A & $\begin{array}{l}\text { Trust } \\
\text { Risk }\end{array}$ & $\begin{array}{l}\text { Antecedent and Consequent } \\
\text { (Individual level) }\end{array}$ \\
\hline Okazaki et al. (2009) & Mediator & N/A & $\begin{array}{l}\text { Trust } \\
\text { Risk }\end{array}$ & Consequent (Individual level) \\
\hline Xu et al. (2012) & Consequent & N/A & N/A & Antecedent (Individual level) \\
\hline Yang and Liu (2014) & Mediator & N/A & $\begin{array}{l}\text { Trust } \\
\text { Risk }\end{array}$ & Consequent (Individual level) \\
\hline This study & Mediator & $\begin{array}{l}\text { Antecedent (Individual level) } \\
\text { (PDI, IND, MAS, UAI, LTO) }\end{array}$ & $\begin{array}{l}\text { Trust } \\
\text { Risk }\end{array}$ & Consequent (Individual level) \\
\hline
\end{tabular}

(IND - individualism-collectivism, PDI - power distance, UAI - uncertainty avoidance, MAS - masculinity-femininity and LTO - long-term orientation)

(assertiveness, group collectivism, future orientation, and performance orientation), while Cockroft and Rekker (2015) use all nine dimensions.

Additionally, and perhaps of greater concern, is that not all of these studies measured culture at the individual level, often instead assuming that all members of a particular society share precisely the same values. As Hofstede (2001, p. 15) notes, "In studying 'values' we compare individuals; in studying 'culture' we compare societies." Differences in social organization and social practices, even within the same culture, influence cognitive processes of individuals in that culture (Nisbett, Peng, Choi, \& Norenzayan, 2001), suggesting that variations at the individual level are relevant. The weakness in assuming that all the individuals in a particular culture share the identical values was also highlighted by Dorfman and Howell (1988, pp. 129-130): 
....all the analyses from Hofstede's work reflect an "ecological" level of analysis-correlations among items in each scale and factor analyses used to define the measures use mean scores from respondents aggregated at the national level before being subjected to analysis. In other words, each item in Hofstede's questionnaire produced a single data point (the mean score) for each country in his analysis. Analysis at the individual level reveals an entirely different picture from analysis at the ecological level...The ecological level of analysis severely restricts the meaningfulness and usefulness of the scales for those researchers who operate at the micro level of analysis.

In this research, we measure cultural values at the individual level and include the five Hofstede dimensions listed above. We recruited respondents from India and the United States because Hofstede et al. (2010) found that these countries differed culturally on three of the five dimensions (power distance, individualism, and long term orientation).

It is possible that the cultural values at the country level as studied by Hofstede have shifted since when they were first developed. On the criticism that his data were old, Hofstede responded in a review of the evolution of his cultural dimensions as follows (Minkov \& Hofstede, 2011):

Concerning criticisms to the effect that his data are old, [Hofstede] has always defended the opinion that cultures do evolve but they tend to move together in more or less one and the same cultural direction. Therefore, the cultural differences between them are not necessarily lost, and these differences are what the dimensions describe. The clearest confirmation of the correctness of this position was provided by Inglehart (2008). In an analysis of empirical data from Western European countries spanning the period from 1970 to 2006, he showed that while Western cultures did evolve and even tended to show some incomplete convergence, at least on a number of subjectively selected variables, their paths practically never crossed during those 36 years.

Hofstede concluded that his cultural dimensions have adapted to cultural changes over time and remained progressive. In a separate study, Beugelsdijk et al. (2015) found that cultural change was absolute rather than relative, in that countries' culture scores relative to each other were hardly affected, and that country pair cultural differences (i.e., cultural distances) were relatively stable. Given these arguments and findings as well as the overwhelming use of Hofstede's cultural dimension to this day, we feel comfortable in relying on Hofstede's work. Importantly, by studying cultural values at the individual level, we measure those values as they currently exist among individuals from India and the United States.

We also incorporate individuals' regulatory preferences into a comprehensive model that addresses the complexity of individuals' decision-making. We also include beliefs about both trust in online companies and risk associated with disclosing information to them, which have been identified in the privacy research stream as being especially salient in individuals' privacy-related decisions (Smith et al., 2011). Thus, this study provides and tests a framework to answer the following research questions:

- What is the role of cultural values in driving privacy concerns and related constructs?

- Do privacy concerns affect online disclosure of personal information and regulatory preferences?

- What is the role of trusting beliefs and risk perceptions in mediating the relationships between privacy concerns, online disclosure of personal information, and regulatory preferences?

We explore these relationships in the context of a model grounded in "antecedents - privacy concerns - outcomes" (APCO) framework developed by Smith et al. (2011). As they have noted in convincing manner, a large percentage of empirical privacy research models fit, in one form or another, this dominant research framework that we have come to call as APCO. We therefore ground 
our study of culture and privacy in APCO, and using a sample of consumers from the United States and India, test our model and find strong support for most of our hypotheses.

This study contributes to existing privacy research in three important ways. First, it provides the first test of a model that considers the full set of five cultural dimensions from Hofstede (2001), privacy concerns, trust beliefs, and risk beliefs. Second, it models cultural values as a formative second order construct that represents the composite of the complete set of values and akin to an individual trait-an approach that is unique to this study. Finally, as part of this same model, it tests the impact of these constructs on both personal information disclosure and regulatory preferences.

In what follows, we provide an overview of prior relevant literature to establish a theoretical foundation for studying privacy concerns, cultural values, regulation, information disclosure, trust, and risk in a cohesive framework at the individual level of analysis. Then, we develop the logic underlying our research hypotheses. We then describe the research methodology and findings. The paper concludes with a discussion of key results, directions for future research, and implications for practice.

\section{BACKGROUND ON PRIVACY-RELATED CONSTRUCTS}

Although no previous study has developed and tested a cohesive model that includes privacy concerns, information disclosure, culture, regulation, risk beliefs, and trust beliefs, all have been considered within the research stream in one form or another. In some cases (e.g., privacy concerns) there are numerous studies that have examined the construct and its relationship to others. In others (e.g., privacy regulation), only a sparse amount of attention has been paid to the topic in the past. We briefly review the previous literature in each of these domains in this section and discuss their role in the APCO framework. We first discuss the APCO framework since it plays a central role in our model development.

\section{The APCO Framework}

In an oft-cited interdisciplinary review of privacy research, Smith et al (2011) considered privacyrelated studies from diverse disciplines such as information systems, economics, psychology, marketing, law, philosophy, social science, and political science. They tabulated 320 articles and 128 books and book sections that were published from the 1960s until the early 2010s. They determined that almost all privacy-related empirical research can be viewed within an "antecedents - privacy concerns - outcomes" (APCO) framework. Of course, the antecedents have varied widely across studies, many being in the form of individual traits but others being of a contextual nature. But the outcomes have generally fallen into either the domains of transactional activities (e.g., purchasing from a particular online vendor) or, quite frequently, information disclosure (e.g., revealing types of personal data in response to a query).

Accordingly, we view the APCO framework as robust enough to guide privacy research in the context of cultural values. The longstanding acceptance of the privacy concerns construct, which we discuss next, as the salient underpinning of privacy-related decision-making models suggests that it merits inclusion in a model that aims to understand the relationship between cultural values and information privacy. Further, any model of decision-making behavior should culminate with a dependent variable that is associated with an important real-world behavior. As information disclosure is one of the most frequently embraced dependent variables in empirical privacy research, it seems appropriate to embrace it in a study such as this one. Second, the simplicity of the APCO framework lends it great intuitive appeal, as it can be easily understood by researchers and practitioners alike. As an addition to this framework, we also include variables that were identified by Smith et al (2011) as having been considered in some previous empirical studies and are relevant to our context: trust, risk, and regulation. Because it is impossible to postulate and test a model containing even a modest 
number of such antecedents in a study of cultural values and privacy such as this one, we focus our attention on constructs that, in our view, are most likely to be salient to our research questions.

\section{Privacy Concerns}

Since the mid-1990s, most empirical privacy studies in IS have included a construct either called or effectively equivalent to "privacy concerns" (Smith et al., 2011), which has been defined as "individuals" concerns about organizational information privacy practices" (Smith et al., 1996, p. 169).

From 1996 to 2013, the fundamental components of the "privacy concerns" construct had frequently been considered to be either four first-order sub-constructs, as has been documented by Smith et al (1996), or a second-order construct defined by those four first-order sub-constructs (Stewart \& Segars, 2002): collection, secondary use, improper access, and errors. Although some modest modifications to the construct were proposed for some more specific purposes (e.g., an Internet users' information privacy concern scale by Malholtra et al. (2004)), it was not until 2013 that Hong and Thong (2013) argued convincingly that the "privacy concerns" construct itself was of a more complex nature than had originally been realized. They identified six dimensions to the construct: the original four plus control and awareness. Further, they created an instrument containing 18 items (three for each dimension) that undergirds a third-order reflective measure of the construct for use in privacy studies, the approach we embrace in this study.

\section{Privacy Concerns and Information Disclosure}

As noted above and by Smith et al (2011), the majority of privacy studies in IS have addressed at least some portion of the APCO framework. The outcome (O) construct in that framework has sometimes been considered to be a willingness to engage in commercial transactions with a certain entity, but more frequently researchers have measured subjects' stated intentions or actual behaviors in disclosing requested information in response to a request. This latter approach appears to be quite salient in the emerging world of social media, in which information disclosure is more important to many business models than are actual transactions. Thus, we also consider information disclosure as one of the outcome variables in this study.

No single template for the information disclosure construct has emerged in the literature stream. Most researchers rely on a contextualized definition of the construct by tailoring it to the specific domain of their study. For example, a study associated with healthcare privacy might measure subjects' disclosure of certain medical data such as their height, weight, blood pressure, medications, etc. Similarly, a study associated with financial privacy might measure subjects' disclosure of financial data such as their income, assets, debt, etc.

\section{Privacy and Regulation}

As can be seen in Table 1, three studies have considered governmental regulation in some form as an antecedent to privacy concerns at the individual level of analysis: Lwin et al (2007) measured perceptions regarding the adequacy of existing regulation, Miltgen and Smith (2015) measured knowledge regarding existing regulation, and Xu et al (2012) manipulated subjects' perceptions of regulation by providing different information about regulation to different subjects. More frequently, however, a subject's preferences regarding regulation has been viewed as an outcome variable that is impacted in some way by privacy concerns and, sometimes, other mediating or moderating variables (Bellman et al., 2004; Milberg et al., 2000; Miltgen \& Smith, 2015; Okazaki et al., 2009; Yang \& Liu, 2014). The logic of this latter approach is compelling, as one would expect the largely reactive nature of the regulatory process (Smith, 1994) to reflect responses to privacy concerns in the populace.

One of the complications associated with regulation as a measure-either as an antecedent or an outcome-is that most regulation occurs at the national level, while privacy concerns are generally accepted to be at the individual level. Although one might attempt to construct a composite national measure of privacy concerns, such an approach has traditionally been effected only via public opinion 
polling, which does not usually yield well-validated measures that can withstand rigorous research scrutiny. Thus, it is helpful to embrace an individual measure-logically, regulatory preferences-so that there is consistency across an individual-level model.

\section{Privacy and Cultural Values}

As noted above, our model is derived and tested at the individual level of analysis. Although three previous studies did attempt to test a relationship between culture at a national level and privacy concerns at an individual level (Bellman et al., 2004; Cho et al., 2009; Milberg et al., 2000), we instead focus our attention on two previous studies that measured both at the individual level (Cao \& Everard, 2008; Lowry et al., 2011).

Cao et al (2008) posited relationships between three of the Hofstede cultural indices and privacy concerns and found significance for two of the three (PDI and UAI). Lowry et al (2011) examined relationships between four of the Hofstede cultural indices and privacy concerns; their results indicated significant relationships for two of the four (UAI and IND), but ironically not for PDI, as was found by Cao et al (2008). Neither of these studies considered the full complement of the five Hofstede (2001) indices in a consolidated fashion.

Although the two studies that measured cultural values at the individual level (Cao \& Everard, 2008; Lowry et al., 2011) treated the indices as independent values, two studies that measured culture at the national level (Bellman et al., 2004; Milberg et al., 2000) viewed the cultural indices as forming a composite score that represented the overall culture..$^{5}$ In our view, the "composite" approach taken by Bellman (2004) and Milberg (2000), while weakened by its reliance on national indices, is a more compelling one in terms of viewing cultural perceptions as a set of values that collectively define a subject's cultural values or orientation. Two prior studies focused on Chinese cultural values, measured at the individual level, similarly modeled cultural values as a broader and more encompassing second order construct with six sub-dimensions of Asian culture as first order factors (Kim, Yang, Atkinson, Wolfe, \& Hong, 2001; Qian, Razzaque, \& Keng, 2007).

The original approach taken by Hofstede (1980) and Hofstede (2001) could also be said to support either approach, since he gathered his data in a composite form but did discuss the cultural indices independently in certain contexts. From the standpoint of parsimonious modeling, the composite approach is clearly preferable, since treating each cultural index as an independent construct vastly complicates a research model. In this study, while we gather data regarding cultural values at the individual level as did Cao et al (2008) and Lowry et al (2011), we hypothesize and analyze cultural values as a composite of the five indices from Hofstede (2001). Later, we will see that our composite approach is manifested in our research model as a second-order formative construct for cultural values.

\section{Trust and Risk}

Despite their importance having been noted by Smith et al. (2011), it is the exception rather than the norm for cross-national privacy studies to include constructs related to trust and/or risk as moderating/ mediating constructs. ${ }^{6}$ Dinev et al (2006) found, in a model that included privacy concerns, that there is a significant relationship between institutional trust and self-disclosure in social media. The model employed by Krasnova et al (2012) also included privacy concerns, and they found significant relationships between both institutional trust and trust in other social media network members and self-disclosure. Miltgen and Smith (2015) included a trust measure that combined trust in both regulators and companies, and they found a significant relationship between that construct and "privacy risk concerns," which intermingled privacy concerns and risks. Okazaki et al (2009) tested linkages between privacy concerns, trust, and perceived risk, and they found significant support for all those relationships. Yang and Liu (2014) found significant support for relationships between privacy concerns and trust and between privacy concerns and perceived risk, but the trust and perceived risk constructs were not correlated at a significant level. Although the treatment in these five studies has 
hardly been systematic and consistent, some interesting relationships have been uncovered on those few occasions when trust and/or risk have been included in these models.

The importance of both trust and risk in the overall APCO research framework is now acknowledged (Smith et al., 2011). Thus, we argue that models that look across the spectrum that includes privacy concerns, cultural values, and regulation should include both trust and risk, as we do in this study.

\section{Looking Across Previous Research}

Looking across the previous research stream, we can conclude that, relative to other types of empirical privacy-related studies, very limited attention has been devoted to issues associated with the regulation of privacy and cross-cultural differences. Even when those topics have been addressed, it has typically been done in a piecemeal fashion, with no effort having been devoted to the development of an overarching model that incorporates all salient constructs. In keeping with the APCO framework described by Smith et al (2011), we hold that such an overarching model should be established at the individual level and should include cultural values, privacy concerns, trust, risk, information disclosure, and regulatory preferences. In this study, we develop and test such an overarching model, and it is to that task that we now turn.

\section{RESEARCH MODEL AND HYPOTHESES}

Our research model follows the APCO framework such that cultural values serve as an antecedent to privacy concerns and also impact some other constructs. Because our objective is to better understand the relationships with regulation and behavioral outcomes, however, we focus our development more on the $\mathrm{PC} \rightarrow \mathrm{O}$ linkages than on the $\mathrm{A} \rightarrow \mathrm{PC}$ relationships. Ultimately, privacy concerns impact two outcome variables - behavior and regulation - with some intervening relationships with trust and risk beliefs (see Figure 1). To the extent possible, we refer to previous theoretical development embraced by other researchers. In cases where previous research offers little theoretical insight, we provide our own argumentation as support. We now discuss each of our seven hypotheses.

\section{CULTURAL VALUES' IMPACTS}

\section{Cultural Values and Information Privacy Concerns}

Milberg et al (2000) provided early theoretical support for the linkage between cultural values and information privacy concerns by arguing that previous findings regarding impacts on privacy concerns of individual traits (e.g., paranoia and cynical distrust, as were employed by Smith et al (1996)) could be conceptually extended to include individuals' perceptions of cultural values, which are also analogous to personality at a collective level.

A set of granular theoretical justifications was provided by Lowry et al (2011), who addressed four of the five Hofstede (2001) cultural indices. It was argued that individuals who embrace the cultural value of masculinity (MAS), because of a strong focus on achievement, will "understand the need to forego a certain amount of privacy" (Lowry et al., 2011, p. 174) and will therefore exhibit lower privacy concerns. Endorsing the earlier argument of Cao and Everhard (2008), Lowry et al (2011) argued that individuals who place a high value on uncertainty avoidance (UAI) will avoid uncertainty about their personal information by desiring to limit access by others, thus leading to higher privacy concerns. Lowry et al (2011) also argued that individuals who value large power distance (PDI) will exhibit lower levels of privacy concern, since the hierarchical nature of the organizational structures will favor authority and control, and restricted exchange of knowledge will be accepted. And Lowry et al (2011) argued that lower scores for individualism (IND) will be negatively associated with privacy concerns through reliance on the fact that individualism is often correlated with masculinity 


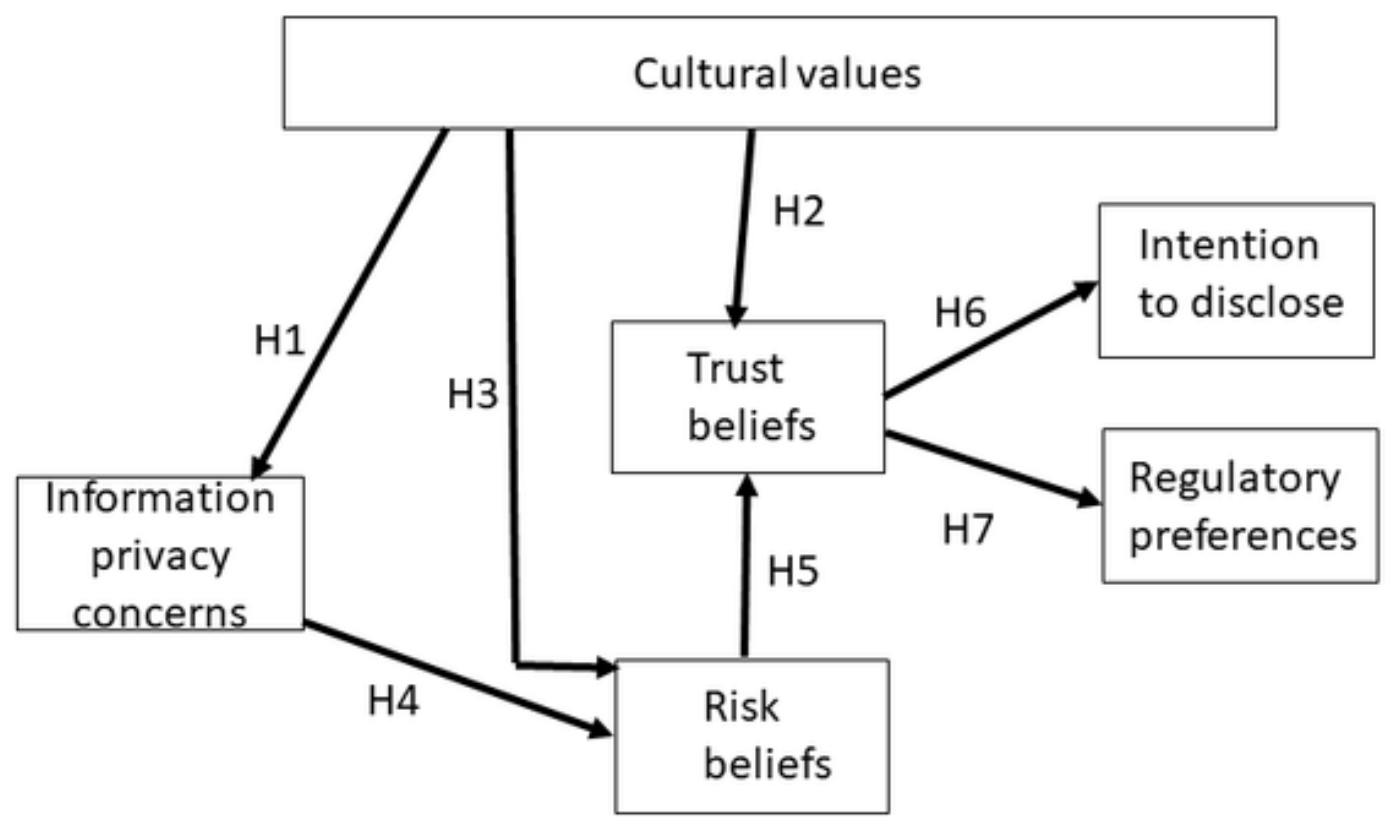

(discussed above). Lowry et al (2011) found empirical support for only two of these four arguments, UAI and IND. Because their study did not include the cultural value of long-term orientation (LTO), they did not provide a theoretical argument for its linkage to privacy concerns.

While it is apparent that cultural values do influence privacy concerns, the limited empirical support for these granular theoretical postulates, coupled with the general analogy to individual traits made by Milberg et al (2000) and prior second order cultural values models (Kim et al., 2001; Qian et al., 2007), lead us to avoid granular prediction at the level of individual cultural value dimensions. Instead we rely on the inference-supported by the fact that at least some of the cultural indices have been shown to be associated with privacy concerns in each of the previous studies that tested the relationship - that the relationship between cultural values and privacy concerns is best expressed in a single non-directional hypothesis:

H1: Cultural values will impact privacy concerns.

\section{Cultural Values and Trust}

A few studies have provided empirical evidence of some between-country differences in trust perceptions and behaviors (e.g. Akai \& Netzer, 2012; Branzei, Vertinsky, \& Camp, 2007; Kuwabara et al., 2007; Paxton, 2007) but without any consideration of overriding cultural values that may explain such differences, and therefore their contribution to theoretical understanding of the phenomenon has been limited. Although well outside the domain of our present endeavor, Takahashi et al. (2008) relied on country-level assumptions about culture to provide insights into different types of collectivism (long-term assurance networks as in Japan versus guanxi-based approaches to building new social networks as in China).

Of more interest to this research are studies that have examined how higher-level cultural values as defined by Hofstede $(1980,2001)$ translate into trust perceptions/behaviors. To date, these studies have focused exclusively on the individualism value and have not considered any of the other four 
cultural indices identified by Hofstede (2001). Buchan et al (2002) measured individual values and found differences across four countries' subjects in terms of their trusting behaviors towards neighbors versus strangers. Buchan et al (2006) showed that students in four countries (China, Korea, Japan, U.S.) exhibited different trusting behaviors in an experiment, and-because the Chinese students behaved in a significantly more trusting fashion-linked this to collectivism.

Branzei et al (2007) did not measure any cultural values at the individual level, but their study did provide a theoretical justification for the relationship between individualism and trusting beliefs. Their argument holds that individuals rely in different measure on dispositional ("individual attributes of the trustee, such as expertise and honesty" (Branzei et al., 2007, p.61)) and contextual (that "qualify the nature, scope, and depth of partners' interactions" (Branzei et al., 2007, p. 61)) signs in making their trust judgments. Dispositional signs include professional designations and indications of ability, whereas contextual signs include membership in a similar group and a relationship with another person who is already known to the judger. Branzei et al (2007) argue that individualists, who will be focused primarily on outcomes and performance, will grant trust based on what they predict will be most highly associated with positive results - that is, situational signs. Collectivists, on the other hand, will seek predictable and benevolent interactions, so they will rely more on contextual signs. Their results largely bore out these theoretical predictions.

Unfortunately, there appears to have been little theoretical linkage in previous research between the other cultural values and trust. We argue that the full context of one's value set-which will also include value judgments regarding uncertainty avoidance, masculinity, etc.—-should also be salient. We therefore propose this broader hypothesis:

H2: Cultural values will impact trust beliefs.

\section{Cultural Values and Risk Beliefs}

We are aware of only four previous studies that have examined the relationship between cultural values and risk, and none of the four provides significant guidance for our immediate endeavor. Cook et al (2005) conducted an experiment to examine differences in U.S and Japanese approaches to risk-taking. They found that Americans were significantly more inclined to take risks than were the Japanese subjects. Although they did reflect on uncertainty avoidance (Hofstede, 2001) as motivation for their study (they argued that Japanese subjects, who are desirous of a less uncertain environment, will eschew risky behaviors), they did not derive hypotheses, per se. It should be noted that this study focused on subject behaviors rather than their beliefs or perceptions.

James et al (2017) focused on the risk associated with exposing others' information on online social networks. In that context, they claimed that the IND index would be salient in explaining risk perceptions associated with such exposure. Specifically, they argued that collectivists perceive risks as being less threatening because they believe a group will lend support in the event of an adverse consequence. This was termed a "cushion hypothesis" (that people in a collectivist society are more likely to receive help in a crisis if they need it) by Hsee and Weber (1999) and Weber and Hsee (1998). In fact, James et al (2017)'s findings did support this hypothesis. It should be noted that James et al (2017), Hsee and Weber (1999), and Weber and Hsee (1998) referred to only the relationship of the IND index to risk and did not explore relationships for the other indices.

Despite the limited amount of previous research on this relationship, we argue that a subject's cultural values - particularly as manifested in indices such as UAI, IND, and MAS — are likely to be associated with risk beliefs in the privacy domain. In our view, the relationship with UAI is virtually tautological. It is also likely that those who value individualism will embrace a more entrepreneurial approach, which will be associated with their approach to risk. Those who value masculine traits should also be more assertive and more comfortable with risk-taking. While these conjectures regarding individualism and masculinity are largely exploratory, there is ample reason to view a subject's overall cultural value set as salient in affecting their risk beliefs. Hence, we hypothesize: 
H3: Cultural values will impact risk beliefs.

\section{Privacy Concerns, Risk Beliefs and Trust Beliefs}

We are unaware of any previous cross-cultural study that has tested the relationship between privacy concerns and risk beliefs as two separate constructs. However, Miltgen and Smith (2015) measured a construct that appeared to intermingle privacy concerns and risk beliefs, and they found that relationships between that risk-related construct and other variables were similar to those one would associate with privacy concerns. While the two constructs are not isomorphic (one might be concerned about privacy, for example, even if one did not perceive any risks in a particular context), a cognitive connection between the two can be expected: individuals who are more concerned about privacy will likely be more attuned to risks that may accompany data collection and use. Therefore, we hypothesize:

H4: Higher levels of privacy concerns will be associated with stronger risk beliefs.

The relationship between trust and risk is elusive and contextual. Likewise, the roles of trust and risk in information privacy research are not consistently represented. (Mayer, Davis, \& Schoorman, 1995, p. 712) state "Trust is not taking risk per se, but rather it is a willingness to take risk." This implies that knowledge of risk precedes trust. Prior studies support this assertion (Arnold, Benford, Hampton, \& Sutton, 2014; Bansal et al., 2010; Dinev \& Hart, 2006; Liao, Liu, \& Chen, 2011).

Dinev and Hart (2006) found that risks associated with opportunistic behavior related to the personal information collected by Internet sites negatively influence individuals' willingness to disclose personal information (trust) required to perform Internet transactions. Liao et al. (Liao et al., 2011) also found strong support for the negative impact of on Internet shoppers' perceived risk of the misuse of personal information on trusting websites with that information. Another study found that the general perception of risk of disclosing personal health information online has a strong negative influence on trust in a specific health website (Bansal et al., 2010). We offer a hypothesis consistent with this research stream:

H5: Stronger risk beliefs will be associated with weaker trust beliefs.

\section{Trust Beliefs and Outcome Variables}

To the best of our knowledge, of the prior published studies that have examined the direct linkage between trust beliefs and the outcome variable of disclosure, only two have provided a theoretical argument for the linkage. ${ }^{7} \mathrm{Xu}$ et al (2005) relied on the theory of reasoned action (Ajzen, 1991) as interpreted by Jarvenpaa et al (2000) to argue that "trust, viewed as [a] positive antecedent belief, [is] expected to affect a person's attitude that in turn influences a person's behavioral intention" (H $\mathrm{Xu}$ et al., 2005, p. 902). In their study, behavioral intentions were measured in terms of disclosure intentions for a location-based services offering. Metzger (2004) examined actual website disclosure and found that such disclosure was strongly associated with trust in the website; as did Xu et al (2005), they explained this through an appeal to the theory of reasoned action (Ajzen, 1991). In the same vein, we hypothesize:

H6: Stronger trust beliefs will be associated with higher levels of information disclosure intentions.

To the best of our knowledge, no prior study has tested the relationship between trust beliefs and regulatory preferences. However, given prior research and expected relationships between privacy concerns and trust beliefs, we can infer that, just as higher privacy concerns lead to desire for more governmental regulation (e.g., Milberg et al., 2000), so will weaker trust beliefs. As individuals perceive 
that they cannot trust entities to act in a trustworthy manner of their own accord, they naturally desire protection in their relationships with those entities. This leads to our final hypothesis:

H7: Weaker trust beliefs will be associated with stronger desires for additional governmental privacy regulation.

Having now developed our research model, we turn to the method of our study.

\section{METHODS}

We developed a survey and validated through a series of data collections using Qualtrics and Amazon's Mechanical Turk (MTurk). We then employed Qualtrics and MTurk to implement the final survey to test the hypotheses. We leveraged the MTurk platform to recruit a diverse group of participants that potentially exhibit differences in cultural values. The following subsections provide the details of the measurement development and implementation.

\section{Measures}

We used items either directly or adapted from previously developed and validated instruments as the basis for measuring the constructs of interest in this study. Appendix A lists all items, which were measured on 1-to-5 Likert scale. The prompt for the items for Intention to Disclose were "to what extent do you intend to use the Internet to do the following activities," and the scale anchors were "Not at All" and "To a Great Extent." All other items in the instrument used the prompt "Please indicate the extent to which you agree or disagree with the following statements." The anchors were "Strongly Disagree" and "Strongly Agree."

Table 2 summarizes the sources of the items for each dimension. All items used the individual as the unit of analysis. The measures for the cultural dimensions were adapted primarily from Dorfman and Howell (1988), Srite and Karahanna (2006), and Sharma (2010), although some items were taken from Yoo et al. (2011), and one was included from Furrer et al. (2000). Items from Hong and Thong (2013) measured concern for information privacy (CFIP), trust beliefs, and risk beliefs. Dinev and Hart (2006)'s items were adapted for intention to disclose, and items from both Lwin et al. (2007) and Poortinga and Pidgeon (2005) were the basis for the regulation measures.

The measures were developed, refined and ultimately validated through a series of pilot tests, each resulting in refinements of both the survey items and the implementation of the survey on Mturk and Qualtrics. Table 3 summarizes three different surveys of online consumers that were administered over a period of 12 months. We used Hofstede's indices of national culture dimensions (Hofstede, $1980,2001)$ in the first pilot test but then adapted items previously used in the literature to capture Hofstede's dimensions at the individual level ${ }^{8}$ (please see our earlier discussion regarding different levels of analyses). The purpose of the second survey was to validate these culture as well as regulation measures. After minor modifications and refinements, we ran the third survey that included all the items needed for this study.

\section{Survey Implementation}

The final survey was developed in Qualtrics and administered to both U.S. and Indian consumers through MTurk. ${ }^{9}$ We selected the MTurk platform to recruit participants, as this platform allows researchers to reach a geographically and demographically diverse participant pool with considerable variation in age. To improve response quality, MTurk workers were required to have a "hit approval rate" of $95 \%$ or higher, where this rate represents the proportion of completed tasks that are approved by MTurk requesters. Furthermore, each MTurk worker had to have completed at least 50 tasks before taking the survey. We published our survey on the MTurk platform on May 16, 2016 in the 
Table 2. Origins of Measurement Items

\begin{tabular}{|c|c|}
\hline Construct & Source \\
\hline $\begin{array}{l}\text { Culture (second order formative) } \\
\text { Masculinity/Femininity } \\
\text { Long Term Orientation -Planning } \\
\text { Long Term Orientation - Tradition } \\
\text { Individualism/Collectivism } \\
\text { Power Distance } \\
\text { Uncertainty Avoidance }\end{array}$ & $\begin{array}{l}\text { Adapted from (Dorfman \& Howell, 1988; Furrer, Liu, \& } \\
\text { Sudharshan, 2000; Sharma, 2010; Srite \& Karahanna, 2006; } \\
\text { Yoo, Donthu, \& Lenartowicz, 2011) } \\
\text { Adapted from (Dorfman \& Howell, 1988; Furrer et al., 2000; } \\
\text { Sharma, 2010; Srite \& Karahanna, 2006; Yoo et al., 2011) } \\
\text { Taken from Sharma, 2010 } \\
\text { Taken from (Dorfman \& Howell, 1988; Furrer et al., 2000; } \\
\text { Sharma, 2010; Srite \& Karahanna, 2006; Yoo et al., 2011) } \\
\text { Taken from (Dorfman \& Howell, 1988; Furrer et al., 2000; } \\
\text { Sharma, 2010; Srite \& Karahanna, 2006; Yoo et al., 2011) } \\
\text { Some items taken from (Dorfman \& Howell, 1988; Furrer et } \\
\text { al., 2000; Sharma, 2010; Srite \& Karahanna, 2006; Yoo et al., } \\
\text { 2011) and one item adapted from Yoo et al, } 2011\end{array}$ \\
\hline $\begin{array}{c}\text { IPC (third order reflective) } \\
\text { Collection } \\
\text { Errors } \\
\text { Secondary Usage } \\
\text { Improper Access } \\
\text { Control } \\
\text { Awareness }\end{array}$ & Taken from (Hong \& Thong, 2013) \\
\hline Trust beliefs & Adapted from (Hong \& Thong, 2013) \\
\hline Risk beliefs & Adapted from (Hong \& Thong, 2013; Okazaki et al., 2009) \\
\hline Intention to disclose & $\begin{array}{l}\text { Adapted from (Dinev \& Hart, 2006) plus some items developed } \\
\text { by this study }\end{array}$ \\
\hline Regulatory preferences & $\begin{array}{c}\text { Three items taken from (Lwin et al., 2007; Poortinga \& } \\
\text { Pidgeon, 2005) and three items adapted from (Lwin et al., } \\
\text { 2007; Poortinga \& Pidgeon, 2005) }\end{array}$ \\
\hline
\end{tabular}

Table 3. Data Collection

\begin{tabular}{|c|c|c|}
\hline Sample \# & n of Sample* & Date Collected \\
\hline 1 (pilot) & 315 & May 2015 \\
\hline 2 (pilot) & 248 & March 2016 \\
\hline 3 (final) & 256 & May 2016 \\
\hline
\end{tabular}

U.S. and May 17, 2017 in India, and all MTurk participants in those countries who satisfied the above criteria could take our survey as long as it was online. Our quota was filled within three hours in both countries. MTurk participants from the U.S. who completed our survey in one sitting were paid $\$ 1.50$, and those from India were paid $\$ 1.25 .{ }^{10}$ We monitored the quality of responses through attention filters and total time spent on each page. Of the 256 responses total, we removed 72 that did not meet a minimum level of quality, for reasons such as missing attention filters, spending too little time on certain pages of the survey, or answering survey questions in an obviously random manner.

Demographic information concerning the 184 subjects who completed the final survey is shown in Table 4. 
Table 4. Subject Demographics

\begin{tabular}{|c|c|c|}
\hline Demographics & Attribute & N \\
\hline Country & India & 83 \\
\hline & United States & 101 \\
\hline Gender & Male & 714 \\
\hline Ethnicity & Female & 79 \\
\hline & White & 96 \\
\hline & Asian & 7 \\
\hline Age & Hispanic & 4 \\
\hline & over 55 & 16 \\
\hline & 46 to 55 & 37 \\
\hline & 36 to 45 & 127 \\
\hline
\end{tabular}

\section{ANALYSIS}

We utilized the Partial Least Squares (PLS) technique--specifically, SmartPLS version 3.2.4--to analyze the data (Ringle, Wende, \& Becker, 2015). Given our sample size and the complexity of the theoretical model, the use of PLS is appropriate (Chin \& Newsted, 1999).

We confirmed the measurement model through PLS by testing for item and scale reliability, internal consistency, and convergent/discriminant validity. Appendix B shows the loadings of all indicators on their intended constructs as well as their cross-loadings on other constructs for the research model.

For adequate item reliability, ideally, all item loadings should be higher than .707. Individual items with slightly lower loadings are usually acceptable provided that loadings for other items measuring the construct are greater than .707 (Chin \& Newsted, 1999). All but three of the 67 item loadings in the model exceeded .707. Two of the three below .707 were from the established cultural dimension scales. Both were very close to the threshold at .698 (IA4) \& .702 (UA1). Each was retained. The remaining item from intention to disclose (ITD1) was also very close at .662. We reviewed this item for face validity, and a re-run of the model without the item showed that there were no differences in the structural model results. Based on this analysis, we retained this item in an effort to capture as much of the meaning of the intention to disclose construct as possible.

To assess scale reliability and internal consistency, we considered the composite reliability (CR) score and the average variance extracted (AVE). For adequate reliability, the CR score should be greater than .70 in exploratory research or .80 in more mature streams of research (Fornell \& Larcker, 1981). All of our CR scores exceeded .83. In addition, all AVE scores exceeded the recommended level of .50 (Chin et al. 1999). The AVEs for the first order factors ranged from .58 to .88. The AVE for CFIP (.84) was calculated by averaging the R-squared values of the six reflective first order constructs. The CR and AVE scores for the first order factors are shown in Table 5.

We performed two tests for discriminant validity. First, we examined the cross-loadings of the items (see Table 5) to ensure that: (1) each item loaded more highly on its own construct than on any other construct, and (2) each item loaded at least .10 higher on its own construct than all other constructs (Gefen \& Straub, 2005). All measures passed both of these tests. Second, we compared the square root of each construct's AVE to the correlations between that construct and all other constructs to ensure that the square roots of the AVEs exceeded the other correlations. All measures passed this test as well. The square roots of the AVEs are in bold on the diagonal in Table 5. 
We used two tests for common methods bias (CMB). First, we performed Harman's one-factor test (Harman, 1967) to assess the extent of common method variance (CMV), which when excessive can identify common method bias. We found that the measures loaded on 11 separate factors with an eigenvalue greater than 1, and none of the extracted factors explained more than $25.6 \%$ of the overall variance, suggesting that CMV is not a concern according to Harman's one-factor test. A second approach to determining CMV is to include individual measures that are theoretically unrelated to at least one other measure in the survey. When CMV is not present, the predicted correlation between these measures is zero. Lindell and Whitney (2001) concluded that this zero-correlation measure can be identified ad hoc in the absence of such a pre-determined variable by using the smallest correlation among manifest variables in the model as a proxy for determining CMV. Their method proposes to adjust for CMV by adjusting the correlations among all the measures using this proxy. When the proxy is small or zero as predicted, the effect of the adjustment on the correlation matrix is also very small or zero. Several correlations between manifest variables in this study were .001 , which suggests that CMV is not a concern according to the approach described in Lindell and Whitney (2001).

Finally, to ensure that collinearity was not a problem, we examined the variance inflation factor (VIF) for each combination of predictor constructs in the model. The VIFs of all combinations were less than 1.92, well below the recommended maximum threshold of 5 (Hair, Hult, Ringle, \& Sarstedt, 2017).

\section{RESULTS}

Table 6 and Figure 2 show the results of the test of our model. As the findings reveal, cultural values influence CFIP negatively $(\mathrm{p}<.05)$ and trust beliefs positively $(\mathrm{p}<.001)$, supporting H1 and H2. The hypothesized influence of cultural values on risk beliefs (H3) was not supported. CFIP strongly impacts risk beliefs ( $\mathrm{p}<.001)$, risk beliefs negatively influence trust beliefs $(\mathrm{p}<.001)$, and trust beliefs significantly impact both intention to disclose and regulatory preferences, providing strong support for $\mathrm{H} 4, \mathrm{H} 5, \mathrm{H} 6$ and $\mathrm{H} 7$.

Overall, the model appears quite robust, as it explained $64 \%$ and $61 \%$ of the variance in risk and trust beliefs, respectively, and $48 \%$ of the variance in regulatory preferences. The model has less predictive power in predicting the intention to disclose, having explained only $11 \%$ of the variance, and it explained only $3 \%$ of the variance in privacy concerns. Six of our seven hypotheses received statistical support. Only hypothesis $\mathrm{H} 3$, which predicted that cultural values would impact risk beliefs, did not. This suggests that a post hoc analysis of cross-national differences may be useful, so we therefore turn to an examination thereof.

\section{Post Hoc Analysis}

Although the unit of analysis was at the individual level, we were curious how the individuals from the two countries compared and if those results aligned with those of Hofstede. This section describes those results which motivate a suggested extension of this work discussed as Extension 3 in the Implications for Research section of the paper, as this study was not designed to make country-level comparisons.

In order to see if our measures for various dimensions of cultural values were consistent with Hofstede's indices at the national level, we compared factor scores for respondents from the U.S. and India using a t-test. As Table 7 shows, there are significant differences between the two countries in power distance, individualism/collectivism, and long-term orientation. These differences are in directions consistent with indices reported by Hofstede for these two countries. We also find India to be higher than the U.S. in masculinity/femininity and uncertainty avoidance, whereas the two countries are similar in these dimensions according to Hofstede, with the U.S. scoring slightly higher than India. This could be because people in the U.S. have become less masculine and more comfortable with uncertainty since Hofstede did his study. 


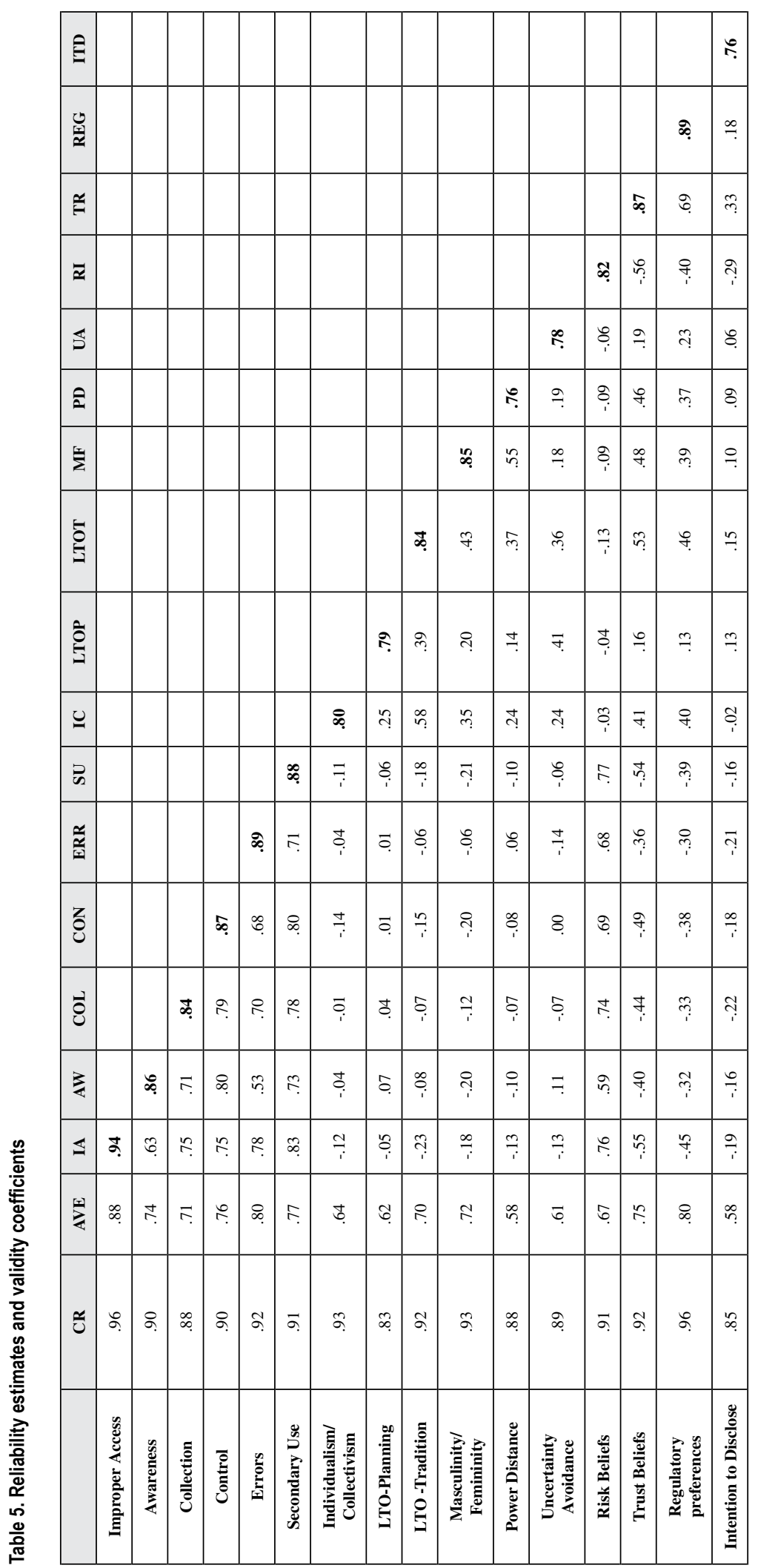


Table 6. Hypotheses test results

\begin{tabular}{|c|c|c|c|c|c|}
\hline Hypothesis & Relationship & $\begin{array}{c}\text { Path } \\
\text { Estimate }\end{array}$ & T Stat & $\begin{array}{c}\text { Significance } \\
\text { Level }\end{array}$ & Supported \\
\hline H1 & Culture -> CFIP & -0.17 & 2.15 & $<.05$ & Yes \\
\hline H2 & Culture - > Trust beliefs & 0.55 & 10.87 & $<.001$ & Yes \\
\hline H3 & Culture -> Risk beliefs & 0.02 & 0.44 & N.S. & No \\
\hline H4 & CFIP -> Risk beliefs & 0.81 & 26.35 & $<.001$ & Yes \\
\hline H5 & Risk beliefs -> Trust beliefs & -0.50 & 9.85 & $<.001$ & Yes \\
\hline H6 & Trust beliefs -> Intention to & 0.33 & 5.53 & $<.001$ & Yes \\
\hline H7 & $\begin{array}{c}\text { Trust beliefs -> Regulatory } \\
\text { preferences }\end{array}$ & 0.69 & 15.17 & $<.001$ & Yes \\
\hline
\end{tabular}

Figure 2. Path Model $\left({ }^{*} p<.05,{ }^{* *} p<.001\right)$

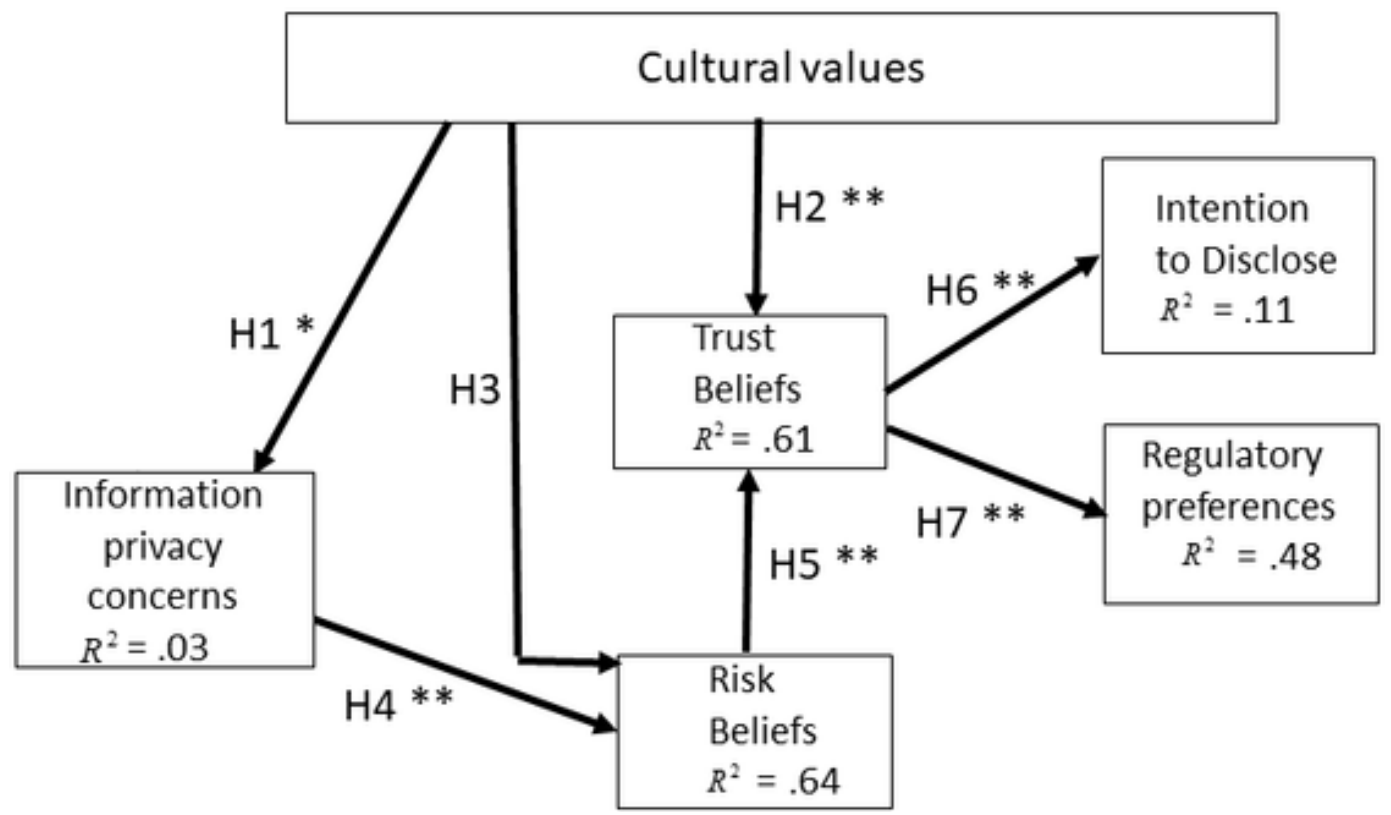

We also checked whether there was any difference between the factor scores of the remaining constructs in the model for the U.S. and India. Table 7 also reports these results. We found that respondents from the U.S. are more concerned about their information privacy, have less trust beliefs than their Indian counterparts. Also, Indian respondents strongly prefer regulation when compared to the U.S. subjects. We did not find a statistical difference between the factor scores of the two groups for risk beliefs and intentions to disclose. 


\section{DISCUSSION}

\section{Reflection on Results}

The model explained only a small portion of the variance in privacy concerns and the intention to disclose. This should not be surprising, given that the model was not designed to fully explain either of those constructs. Indeed, previous research into various portions of the APCO framework has uncovered a myriad of factors that impact both privacy concerns (including numerous individual traits and contextual attributes) and intention to disclose (Smith et al., 2011). Had the immediate model, which was designed primarily to explain the linkage to regulation and the effect of privacy concerns on other constructs, both directly and indirectly, explained large portions of the other constructs, this would have undercut the collective knowledge that has been gained over the last few years across the broader privacy research stream.

Only hypothesis H3, which predicted that cultural values would impact risk beliefs, failed to garner statistical support. As was noted earlier during our derivation of $\mathrm{H} 3$, prior research into this relationship was virtually non-existent, at least at the level it was considered in this study. Only Cook et al (2005), Hsee and Weber (1999), James et al (2017), and Weber and Hsee (1998) had considered this linkage in any form, and none of their prior examinations had been analogous to the model tested here, which looked across the full spectrum of cultural values and included many other constructs. Post hoc analysis of cross-national differences did shed some light on this non-finding (see above). This suggests a need for additional research, an area that will be considered in the following sections.

\section{Contributions}

This study contributes to existing privacy research in three important ways. First it provides the first test of a model that considers the full set of five values from Hofstede (2001), privacy concerns, trust beliefs, and risk beliefs, all measured from the individual unit of analysis. Much past research used country cultural measures as a proxy for individual measures. Second, modeling cultural values as a formative second order construct that represents the composite of the complete set of values and akin

Table 7. Comparison of the factor scores for the U.S. and India

\begin{tabular}{|c|c|c|c|c|c|}
\hline \multirow[t]{2}{*}{ Dimension } & \multicolumn{2}{|c|}{ Mean factor score* } & \multirow[t]{2}{*}{ Significance Level } & \multicolumn{2}{|c|}{ Hofstede Index } \\
\hline & U.S. & India & & U.S. & India \\
\hline Power distance & -.33 & .40 & .001 & 40 & 77 \\
\hline Individualism/collectivism** & -.50 & .62 & .001 & 91 & 48 \\
\hline Masculinity/femininity & -.51 & .60 & .001 & 62 & 56 \\
\hline Uncertainty avoidance & -.20 & .20 & .001 & 46 & 40 \\
\hline Long term orientation & & & & 26 & 51 \\
\hline Planning & -.15 & .18 & .05 & & \\
\hline Tradition & -.45 & .53 & .001 & & \\
\hline CFIP & .19 & -.25 & .01 & & \\
\hline Trust & -.53 & .66 & .001 & & \\
\hline Risk & .10 & -.17 & .10 & & \\
\hline Intention to Disclose & -.04 & .06 & NS & & \\
\hline Regulatory Preferences & -.45 & .55 & .001 & & \\
\hline
\end{tabular}

* Some mean factor scores appear negative because factor scores are normalized around zero.

${ }^{* *}$ Hofstede measures Individualism; we measure Collectivism. 
to an individual trait was unique to this study. Finally, as part of this same model, it tests the impact of these constructs on both personal information disclosure and regulatory preferences.

The findings have implications for both practice and research. We discuss each.

\section{Implications for Practice}

From this study's findings, it is clear that, especially when firms engage in privacy-sensitive endeavors internationally, "one size does not fit all." Differences in cultural values do matter, and while they are often associated with national boundaries, there are also differences between individuals within the same societies. Executives have long since realized that they must be keenly aware of differences in legal expectations surrounding data use when crossing borders-a phenomenon that is especially salient for those who do business in both the U.S. and Europe (Kanter, 2014; Singer, 2013; Smith, 2001). This study suggests, however, that mere compliance with law may not be enough to address privacy-related expectations, since firms that are adhering to legal statutes may still run afoul of consumers' distinctions.

Wherever one is engaging in business worldwide, however, one finding from this study appears especially robust: trust matters. Trust is a strong predictor not only of consumer disclosure behaviors but also consumers' regulatory preferences. Thus, one important piece of advice that transcends national boundaries is this: ensure that steps are taken to increase consumers' privacy-related trust not only in particular firms but also in industries as a whole. In what follows, we discuss how firms and industry associations can cultivate trust among consumers.

\section{Trust in Firms}

It has long been argued that the best way for firms to optimize consumers' trust from a privacy perspective is to embrace the Fair Information Practices (FIPs), as defined over four decades ago (HEW (U.S. Department of Health, 1973). The FIPs are:

1. There shall be no personal data record-keeping systems whose very existence is secret.

2. There must be a way for a person to find out what information about the person is in a record and how it is used.

3. There must be a way for a person to prevent information that was obtained for one purpose from being used or made available for other purposes without the person's consent.

4. There must be a way for a person to correct or amend a record of identifiable information about the person.

5. Any organization creating, maintaining, using, or disseminating records of identifiable personal data must assure the reliability of the data for their intended use and must take precautions to prevent misuses of the data.

Lacking governmental oversight to ensure compliance, it is likely that firms will adhere to FIP 1 but will often dodge FIP 2 (Smith, 1994; Smith, 2001). FIP 3 may be addressed by providing an "opt out" alternative for certain (but not all) such secondary uses. Often due to database design decisions, FIP 4 is usually ignored (Smith, 1994; Smith, 2001). Many firms will make some investment in addressing practice 5, albeit with many lapses (Smith, 1994; Smith, 2001). It is becoming obvious over time, however, that a large percentage of consumers do expect compliance across the set of FIPs, and we urge firms to embrace them even without governmental compliance oversight.

However, simple adherence to these FIPs is not enough if consumers are unaware of a firm's actions. In short, perceptions matter, and firms should wisely invest in communicating with their current and potential consumers to ensure them of their belief in, and compliance with, the FIPs. Many firms, particularly in the U.S., do communicate their privacy policies to their current customers on an annual basis, and some do offer an "opt out" alternative for certain data-sharing practices, although many consumer advocates note that it is sometimes difficult to ascertain exactly how the alternative 
is to be effected. Some display "privacy shields" on their websites, and this indicates that a third party is verifying adherence to the stated privacy policy (Mai, Menon, \& Sarkar, 2010). As will be discussed below, regulatory provisions in many other countries demand greater openness regarding firms' policies and more extensive opportunities for consumers to exercise their choices. It should be noted, however, that communication with current customers is only part of the task, since it is conceivable that some prospective customers may avoid the firm altogether if they are dissatisfied with its privacy posture (Tsai, Egelman, Cranor, \& Acquisti, 2011). Thus, especially for online merchants, clear explanations of privacy policies should be included in prominent position on websites.

\section{Trust in Industries}

Above, we detailed some actions that can be taken by individual firms, but it often the case that consumers form perceptions of entire industries and then project those onto individual companies. Thus, it is trust in industries that may prove more important as consumers form their preferences regarding regulation.

Industry associations are often the best vehicles for the codification and dissemination of agreedupon policies regarding consumer data collection and use. It would behoove firms in data-intensive industries to band together in creating sets of industry-specific FIPs to which they may then hold one another accountable. Assuming that those FIPs are reasonable ones that take consumers' interests into account, broad communication and enforcement thereof could mute consumers' concerns and increase the level of trust in the industry. This, in turn, could reduce the desire for additional government regulation.

\section{Implications for Research}

There are several implications of the findings from this study. Additionally, numerous extensions are also indicated. We discuss both of these areas.

\section{Implications of These Findings}

We did not attempt to create an exhaustive model of the full APCO framework, so it is not surprising that only a very small portion of privacy concerns was explained here. However, this suggests that a much deeper model-one that would include both individual and contextual factors—could prove profitable in explaining the link between antecedents and privacy concerns (A $\rightarrow P C)$. Table 8 details a large number of potential antecedents to privacy concerns as they were identified in oft-cited review articles (Bélanger \& Crossler, 2011; Li, 2011; Smith et al., 2011). Also note that much more attention should be paid to the linkage between cultural values and risk beliefs. As compared to other relationships in our model, that one has received much less attention in the past. We were unable to confirm a specific relationship between cultural values and risk beliefs, but it is conceivable that additional research into this relationship could provide a robust explanation.

\section{Extensions}

The above suggestions were based on the findings of the immediate study. Beyond those, we argue that researchers who are interested in the broad domain of privacy-related studies associated with cultural value differences should also consider the following:

Extension 1 - Other linkages to information disclosure behavior: Our model conformed to the basic APCO framework and viewed privacy concerns, deepened with the inclusion of a relationship between risk and trust beliefs, as being the primary driver of information disclosure behaviors. However, it should be noted that some other variables have been identified as potentially having explanatory relationships with these behaviors (Smith et al., 2011). In particular, should a "privacy calculus" approach be invoked, benefits associated with information disclosures may become 
Table 8. Antecedents to Privacy Concerns ${ }^{11}$

\begin{tabular}{|c|c|c|}
\hline Source & Individual factors & Contextual factors \\
\hline $\begin{array}{l}\text { Bélanger and Crossler } \\
(2011)^{12}\end{array}$ & $\begin{array}{l}\text { Individual differences: } \\
\text { - Demographics (gender, age, education) } \\
\text { - Self-efficacy } \\
\text { - Personality traits (e.g., amicability) }\end{array}$ & $\begin{array}{l}\text { Group dynamics } \\
\text { Government involvement }\end{array}$ \\
\hline $\mathrm{Li}(2011)^{13}$ & $\begin{array}{l}\text { Individual differences: } \\
\text { - Demographic } \\
\text { - Personality traits } \\
\text { - Knowledge and experience } \\
\text { - Computer anxiety } \\
\text { - Computer self-efficacy } \\
\text { - Need for privacy }\end{array}$ & $\begin{array}{l}\text { Social-relational factors: } \\
\text { - Social norms } \\
\text { Macro-environmental factors: } \\
\text { - Culture } \\
\text { - Governmental regulations } \\
\text { Organizational and task } \\
\text { environmental factors: } \\
\text { - Reputation } \\
\text { - Privacy interventions } \\
\text { - Social presence } \\
\text { Information contingency: } \\
\text { - Information sensitivity } \\
\text { - Types of information }\end{array}$ \\
\hline $\begin{array}{l}\text { Smith, Dinev, and Xu } \\
\text { (2011) }\end{array}$ & $\begin{array}{l}\text { Privacy experiences } \\
\text { Privacy awareness } \\
\text { Demographic differences: } \\
\text { - Gender } \\
\text { - Age } \\
\text { - Ethnicity } \\
\text { - Education } \\
\text { - Income } \\
\text { Personality differences: } \\
\text { - introversion/extroversion } \\
\text { - independent self/interdependent-self } \\
\text { - "Big Five" personality traits } \\
\text { - Social awareness }\end{array}$ & $\begin{array}{l}\text { Culture/climate } \\
\text { Situational cues }\end{array}$ \\
\hline
\end{tabular}

salient. Further, the existence of a privacy seal and/or the extensiveness of a firm's privacy policy could also prove impactful.

Extension 2 - Regulatory structures: We focused on the regulatory process in this study, and additional work in this area is certainly warranted. Future research might include not only a consideration of subjects' preferences for regulation but also the actual manner in which different countries regulate privacy.

The differing nature of such regulatory models was explained by Bennett (1992), whose work inspired the research of Milberg, Smith, and Burke (2000). As can be seen in Figure 3, adapted from Smith (2001), countries' regulatory approaches could traditionally be categorized based on the extent to which they provide rights to data subjects and to the extent they involve government in corporate privacy management.

The specific mechanisms for ensuring such rights have varied across countries, with some relying on the "data commissioner" model, in which a separate governmental institution embraces the role of an ombudsperson. The commissioner receives complaints from citizens and investigates these complaints. The commissioner offers advice on data handling; monitors technology and makes proposals; and may inspect some data processing operations. Others have embraced the "Registration" model, in which each databank containing personal data be registered (usually upon payment of a fee) by a separate governmental institution. The governmental institution cannot block the creation of a particular information system but can "deregister" a system based on a complaint and investigation. 
A small number have used the "Licensing" model, which requires that each databank containing personal data be licensed (usually upon payment of a fee) by a separate governmental institution. This institution would stipulate specific conditions for the collection, storage, and use of personal data. This model requires prior approval by the regulatory institution for any use of data.

From a research perspective, one obvious use of this regulatory model mapping would be the categorization of various countries' models, which would serve as an independent variable in a regression analysis that would predict individuals' behaviors and/or regulatory preferences by including other independent constructs that might be clustered around individual or contextual differences. Obviously, to draw substantive conclusions, a sample that crosses a large number of

Extension 3 - Cross-national experiments: Although our post hoc analysis did imply some cultural differences based on national boundaries and did suggest linkages to subjects' reported behaviors, our study viewed the individual as the unit of analysis and was not designed to uncover nationalistic differences in culture or behavior. To the extent that there are behavioral differences to be discovered between citizens of different countries, researchers could run experiments that measured actual behaviors (e.g., self-disclosures, purchase transactions with privacy implications, self-protection behaviors). Such experiments could include measures of individual traits and could also manipulate conditions, such as firms' privacy policies or stated uses for collected information.

Only a very few privacy-related studies have examined actual behaviors to date (e.g., Choi, Jiang, Xiao, \& Kim, 2015; Hui, Teo, \& Lee, 2007; Keith, Babb, Lowry, Furner, \& Abdullat, 2015; Sutanto, Palme, Tan, \& Phang, 2013; Tsai et al., 2011), and we are unaware of any such studies that have looked across national boundaries. However, one can easily envision how such a study might be constructed. For example, consider the single-country experiment conducted by Tsai et al (2011) in which individuals were asked, in a laboratory environment, to make an actual online purchase of a specified product. Privacy policies of online merchants were displayed differently to subjects, who were randomly assigned to treatment groups. It was found that the manner in which privacy policy information is communicated to consumers made a significant difference in their choice of online merchants. Experiments of this type could include cultural values as an explanatory antecedent of behaviors to provide insight into the manner in which difference in these values manifest themselves in actual behaviors. If expanded to multi-country domains the expected increased variation in cultural values would make for deeper insights.

It is also conceivable that such a multi-country experiment could include manipulations intended to impact consumers' perceptions of governmental regulatory protections. For example, in addition to (or instead of) presenting consumers with firms' privacy policy information, an experiment might instead present them with statements regarding governmental regulations and frameworks associated therewith. If the purchase options included firms in different countries with different privacy regulatory structures and protections, this could also impact consumers' purchase decisions.

Extension 4 - Process models: We also note that this study revolved around a variance model, which has been the case for virtually all the previous studies in the privacy research stream. Variance models, which are designed to provide evidence of relationships between constructs in a timeinvariant "snapshot," have yielded many worthy research contributions.

However, much additional knowledge could be gained by employing process models in the privacy research stream. Such models focus not on the manner in which increases/decreases in certain constructs are linked in a single "snapshot" but, rather, in how changes occur over time. This temporal tracing of the process, which entails identification of events that trigger different episodes, can yield a rich understanding of more complex phenomena that are simply unobservable in a single-staged 
Figure 3. Regulation Models ${ }^{14}$ national boundaries would be required, and-given the pending General Data Protection Regulation's (GDPR) homogenization of regulatory models in the EU--the sample should include countries outside of the EU so as to maximize the variance

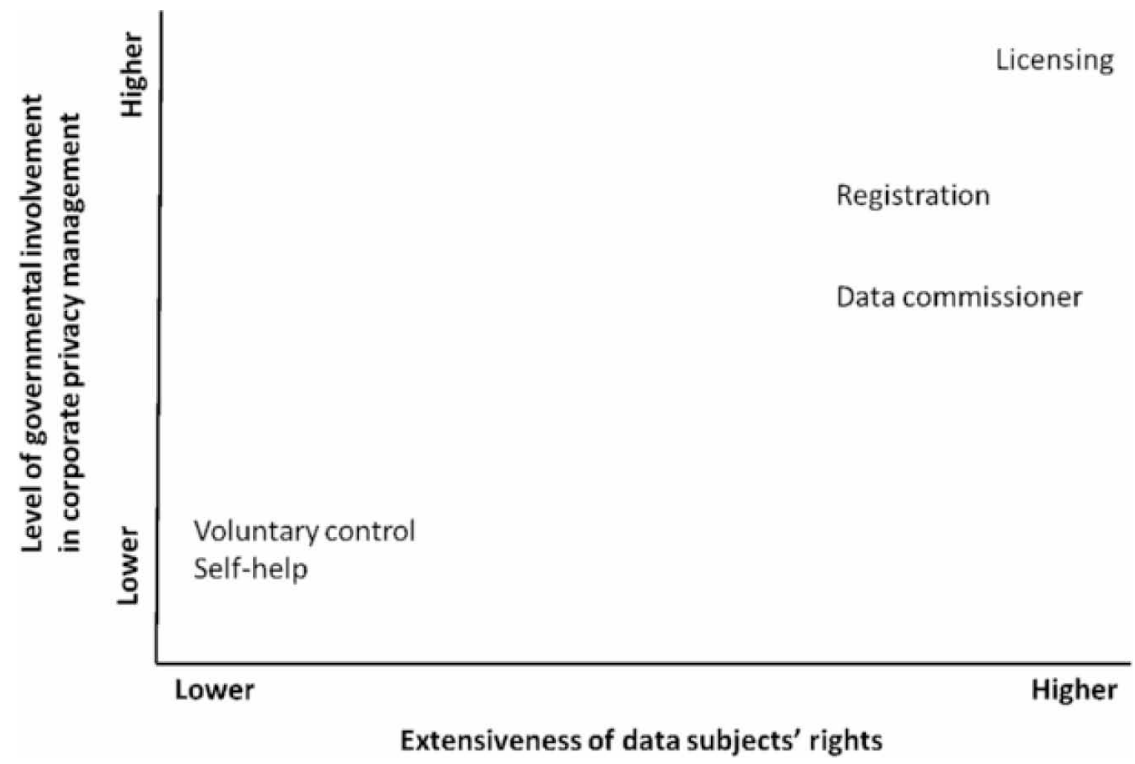

Table 9. See Figure 3

\begin{tabular}{|c|l|}
\hline Model & \multicolumn{1}{c|}{ Description } \\
\hline Self-help & $\begin{array}{l}\text { Depends on data subjects' challenging inappropriate recordkeeping practices, by } \\
\text { identifying problems and bringing them to the courts for resolution. Example: U.S. }\end{array}$ \\
\hline Voluntary control & $\begin{array}{l}\text { Relies on corporate self-regulation. Each organization ensures its own compliance. } \\
\text { Example: U.S. }\end{array}$ \\
\hline Data commissioner & $\begin{array}{l}\text { Creates a separate governmental institution that embraces the role of an ombudsperson. } \\
\text { The commissioner receives complaints from citizens and investigates these complaints. The } \\
\text { commissioner offers advice on data handling; monitors technology and makes proposals; } \\
\text { and may inspect some data processing operations. Example: Germany. }\end{array}$ \\
\hline Registration & $\begin{array}{l}\text { Requires that each databank containing personal data be registered (usually upon payment } \\
\text { of a fee) by a separate governmental institution. The governmental institution cannot block } \\
\text { the creation of a particular information system but can "deregister" a system based on a } \\
\text { complaint and investigation. Example: U.K. }\end{array}$ \\
\hline Licensing & $\begin{array}{l}\text { Requires that each databank containing personal data be licensed (usually upon payment } \\
\text { of a fee) by a separate governmental institution. This institution would stipulate specific } \\
\text { conditions for the collection, storage, and use of personal data. This model requires prior } \\
\text { approval by the regulatory institution for any use of data. Example: Sweden. }\end{array}$ \\
\hline
\end{tabular}

variance model. The very infrequent appearance of such process models in the privacy research stream can likely be traced to the extremely time-consuming nature of their study. Such process models are almost always constructed through careful qualitative interviews (using a method often called "process tracing"), which entails lengthy interviews with various parties over time. Additionally, researchers may secure archival documentation from subjects to enrich what is sometimes called a "thick description" of events and episodes. It is obvious that a cross-national process modeling effort that reveals changes over time in individuals' privacy-related decision-making, corporate privacy policymaking, and/or governmental regulation would be a major contribution to the research stream. 


\section{Limitations}

This study's findings are subject to several limitations. First, we measured disclosure intentions and not actual disclosure behaviors. While our approach is consistent with the vast majority of privacy studies (Smith et al., 2011), we acknowledge the possibility that a subject might ultimate behave in a manner that is inconsistent with his or her stated intentions. However, this potential limitation should not be viewed as critical, since our model also measured regulatory preferences and explained almost half of the variance in that outcome construct. We do note that future studies of this type could be strengthened even further if actual behaviors are measured.

Second, although it might be argued that the fact our data were collected from only two countries (U.S. and India) constitutes a minor limitation. However, cross-national data collection exercises are notoriously complex and difficult, and our embrace of a commonly used data collection technique (recruitment of workers via MTurk) dictated that our sample be restricted to those countries that had a large concentration of MTurk workers - principally, the U.S. and India. As the fundamental unit of analysis in this study was the individual, and because we measured cultural values at the individual level, the dispersion of workers is less of a concern than it would have been for a study that utilized countries as the unit of analysis.

Additionally, the measures we employed for trust and risk beliefs asked about online companies in general. It can be said that referring to such companies as "e-commerce companies" would have better face validity. Also, consumer perceptions of trust and risk likely vary across different companies. Future studies in this domain could focus on specific companies or industries to understand the issues presented in this study in a more granular way.

\section{CONCLUSION}

This is the first study in the privacy research stream to consider the full set of Hofstede (2001) values, measured at the individual level, and their relationship to privacy concerns, trust, risk, and behavioral outcomes of self-disclosure and regulatory preferences. In light of the growing connectivity that reaches seamlessly across national borders, we believe that it is particularly important for researchers to probe more deeply into factors that may impact regulatory preferences and statutory reflections thereof. We hope that this study can be seen as just one of the first steps on a path that others will follow in exploring this under-examined area within the privacy research domain. 


\section{REFERENCES}

Adjerid, I., Peer, E., \& Acquisti, A. (2018). Beyond the Privacy Paradox: Objective versus Relative Risk in Privacy Decision Making. Management Information Systems Quarterly, 42(2), 465-488. doi:10.25300/MISQ/2018/14316

Ajzen, I. (1991). The Theory of Planned Behavior. Organizational Behavior and Human Decision Processes, 50(2), 179-211. doi:10.1016/0749-5978(91)90020-T

Akai, K., \& Netzer, R. J. (2012). Trust and reciprocity among international groups: Experiemental evidence from Austria and Japan. Journal of Socio-Economics, 41(2), 266-276. doi:10.1016/j.socec.2011.08.028

Angst, C. M., \& Agarwal, R. (2009). Adoption of electronic health records in the presence of privacy concerns: The elaboration likelihood model and individual persuasion. Management Information Systems Quarterly, 33(2), 339-370. doi:10.2307/20650295

Arnold, V., Benford, T. S., Hampton, C., \& Sutton, S. (2014). Enterprise risk management: Re-conceptualizing the role of risk and trust on information sharing in transnational alliances. Journal of Information Systems, 28(2), 257-285. doi:10.2308/isys-50812

Bansal, G., Zahedi, F. M., \& Gefen, D. (2010). The impact of personal dispositions on information sensitivity, privacy concern and trust in disclosing health information online. Decision Support Systems, 49(2), 138-150. doi:10.1016/j.dss.2010.01.010

Basu, S. (2010). Policy-Making, Technology and Privacy in India. The Indian Journal of Law and Technology, 6(1), 65-88.

Bélanger, F., \& Crossler, R. (2011). Privacy in the Digital Age: A Review of Information Privacy Research in Information Systems. Management Information Systems Quarterly, 35(4), 1017-1041. doi:10.2307/41409971

Bellman, S., Johnson, E. J., Kobrin, S. J., \& Lohse, G. L. (2004). International Differences in Information Privacy Concerns: A Global Survey of Consumers. The Information Society: An International Journal, 20(5), 313-324. doi:10.1080/01972240490507956

Bennett, C. J. (1992). Regulating Privacy: Data Protection and Public Policy in Europe and the United States. Cornell University Press. doi:10.7591/9781501722134

Beugelsdijk, S., Maseland, R., \& van Hoorn, A. (2015). Are Hofstede's Culture Dimensions Stable over Time?A Generational Cohort Analysis. Global Strategy Journal, 5.

Branzei, O., Vertinsky, I., \& Camp, R. D. II. (2007). Culture-contingent signs of trust in emergent relationships. Organizational Behavior and Human Decision Processes, 104(1), 61-82. doi:10.1016/j.obhdp.2006.11.002

Buchan, N. R., Croson, R. T. A., \& Dawes, R. M. (2002). Swift Neighbors and Persistent Strangers: A CrossCultural Investigation of Trust and Reciprocity in Social Exchange. American Journal of Sociology, 108(1), 168-206. doi:10.1086/344546

Buchan, N. R., Johnson, E. J., \& Croson, R. T. A. (2006). Let's get personal: An international examination of the influence of communication, culture and social distance on other regarding preferences. Journal of Economic Behavior \& Organization, 60(3), 373-398. doi:10.1016/j.jebo.2004.03.017

Buckman, J. R., Bockstedt, J. C., \& Hashim, M. J. (2019). Relative Privacy Valuations Under Varying Disclosure Characteristics. Information Systems Research, 30(2), 375-388. doi:10.1287/isre.2018.0818

Cao, J., \& Everard, A. (2008). User Attitude Towards Instant Messaging: The Effect of Espoused National Cultural Values on Awareness and Privacy. Journal of Global Information Technology Management, 11(2), 30-57. doi:10.1080/1097198X.2008.10856466

Chin, W. W., \& Newsted, P. R. (1999). Structural equation modeling analysis with small samples using partial least squares. In R. Hoyle (Ed.), Statistical Strategies for Small Sample Research (pp. 307-341). Sage Publications.

Cho, H., Rivera-Sánchez, M., \& Lim, S. S. (2009). A multinational study on online privacy: Global concerns and local responses. New Media \& Society, 11(3), 395-416. doi:10.1177/1461444808101618 
Choi, B. C. F., Jiang, J., Xiao, B., \& Kim, S. S. (2015). Embarrassing exposures in online social networks: An integrated perspective of privacy invasion and relationship bonding. Information Systems Research, 26(4), 675-694. doi:10.1287/isre.2015.0602

Cockcroft, S., \& Rekker, S. (2015). The relationship between culture and information privacy policy. Electronic Markets, 26(1), 55-72. doi:10.1007/s12525-015-0195-9

Cockcroft, S., Sandhu, N., \& Norris, A. (2009). How does national culture affect citizens' rights of access to personal health information and informed consent? Health Informatics Journal, 15(3), $229-243$. doi:10.1177/1460458209337444 PMID:19713397

Cook, K. S., Yamagishi, T., Cheshire, C., Cooper, R., Mashima, M., \& Mashima, R. (2005). Trust building via risk taking: A cross-societal experiment. Social Psychology Quarterly, 68(2), 121-142. doi:10.1177/019027250506800202

Dinev, T., Bellotto, M., Hart, P., Russo, V., Serra, I., \& Colautti, C. (2006). Privacy calculus model in e-commerce - a study of Italy and the United States. European Journal of Information Systems, 15(4), 389-402. doi:10.1057/ palgrave.ejis. 3000590

Dinev, T., \& Hart, P. (2006). An extended privacy calculus model for e-commerce transactions. Information Systems Research, 17(1), 61-80. doi:10.1287/isre.1060.0080

Dinev, T., Hart, P., \& Mullen, M. R. (2008). Internet privacy concerns and beliefs about government surveillance - an empirical investigation. The Journal of Strategic Information Systems, 17(3), 214-233. doi:10.1016/j. jsis.2007.09.002

Dorfman, P. W., \& Howell, J. P. (1988). Dimension of National Culture and Effective Leadership Patterns: Hofstede Revisited. In Advances in International Comparative Management (pp. 127-150). JAI Press, Inc.

Farrell, A. M., Grenier, J. H., \& Leiby, J. (2016). Scoundrels or stars? Theory and evidence on the quality of workers in online labor markets. The Accounting Review, 92(1), 93-114. doi:10.2308/accr-51447

Fjetland, M. (2002). Global commerce and the privacy clash. Information Management Journal, 36(1), 54-57.

Flaherty, D. H. (1989). Protecting Privacy in Surveillance Societies. University of North Carolina Press.

Fornell, C., \& Larcker, D. F. (1981). Structural equation models with unobservable variables and measurement error: Algebra and statistics. JMR, Journal of Marketing Research, 18(3), 382-388. doi:10.1177/002224378101800313

Furrer, O., Liu, B. S.-C., \& Sudharshan, D. (2000). The Relationships between culture and service quality perceptions: Basis for cross-cultural market segmentation and resource allocation. Journal of Service Research, 2(4), 355-371. doi:10.1177/109467050024004

Gefen, D., \& Straub, D. W. (2005). A practical guide to factorial validity using PLS-Graph: Tutorial and annotated example. Communications of the Association for Information Systems, 16(5), 39-50. doi:10.17705/1CAIS.01605

Greengard, S. (2018). Weighing the Impact of GDPR. Communications of the ACM, 61(11), 16-18. doi: $10.1145 / 3276744$

Hair, J. F. J., Hult, G. T. M., Ringle, C., \& Sarstedt, M. (2017). A Primer on Partial Least Squares Structural Equation Modeling (PLS-SEM) (2nd ed.). Sage Publications.

Harman, D. (1967). A single factor test of common method variance. The Journal of Psychology, 35, 359-378.

HEW. (U.S. Department of Health, E., and Welfare). (1973). Records, Computers, and the Rights of Citizens: Report of the Secretary's Advisory Committee on Automated Personal Data Systems. Washington, DC: U.S. Government Printing Office.

Hoffman, D. L., Novak, T. P., \& Peralta, M. (1999). Building consumer trust online. Communications of the ACM, 42(4), 80-85. doi:10.1145/299157.299175

Hofstede, G. H. (1980). Culture's consequences: International differences in work-related values. Sage Publications.

Hofstede, G. H. (2001). Culture's consequences: Comparing values, behaviors, institutions, and organizations across nations. Sage Publications. 
Hofstede, G. H., Hofstede, G. J., \& Minkov, M. (2010). Cultures and Organizations: Software of the Mind (3rd ed.). McGraw Hill.

Hong, W., \& Thong, J. Y. L. (2013). Internet Privacy Concerns: An Integrated Conceptualization and Four Empirical Studies. Management Information Systems Quarterly, 37(1), 275-298. doi:10.25300/ MISQ/2013/37.1.12

House, R., Javidan, M., Hanges, P., \& Dorfman, P. W. (2002). Understanding cultures and implicit leadership theories across the globe: An introduction to Project Globe. Journal of World Business, 37(1), 310. doi:10.1016/ S1090-9516(01)00069-4

Hsee, C. K., \& Weber, E. U. (1999). Cross-National Differences in Risk Preference and Lay Predictions. Journal of Behavioral Decision Making, 12(2), 165-179. doi:10.1002/(SICI)1099-0771(199906)12:2<165::AIDBDM316>3.0.CO;2-N

Hui, K. L., Teo, H. H., \& Lee, S. Y. T. (2007). The Value of Privacy Assurance: An Exploratory Field Experiment. Management Information Systems Quarterly, 31(1), 19-33. doi:10.2307/25148779

Inglehart, R. (2008). Changing values among Western publics from 1970 to 2006. West European Politics, 31(1/2), 130-146. doi:10.1080/01402380701834747

International, P. S. R. A. (2005). Leap of faith: Using the Internet despite the dangers. Retrieved from Yonkers. http://consumersunion.org/wp-content/uploads/2013/05/leapoffaith.pdf

James, T. L., Wallace, L., Warkentin, M., Kim, B. C., \& Collignon, S. E. (2017). Exposing others' information on online social networks (OSNs): Perceived shared risk, its determinants, and its influence on OSN privacy control use. Information \& Management, 54(7), 851-865. doi:10.1016/j.im.2017.01.001

James, T. L., Wallace, L., Warketin, M., Kim, B. C., \& Collignon, S. E. (2017, November). Exposing othere' information on online social networks (OSNs): Perceived shared risk, its determinants, and its influence on OSN privacy control use. Information \& Management, 54(7), 851-865. doi:10.1016/j.im.2017.01.001

Jarvenpaa, S. L., Tractinsky, N., \& Vitale, M. (2000). Consumer Trust in an Internet Store. Information Technology and Management, 1(12), 45-71. doi:10.1023/A:1019104520776

Kanter, J. (2014, April 1). A nudge on digital privacy law from EU official. The New York Times.

Keith, M. J., Babb, J. S., Lowry, P. B., Furner, C. P., \& Abdullat, A. (2015). The role of mobile-computing selfefficacy in consumer information disclosure. Information Systems Journal, 25(6), 637-667. doi:10.1111/isj.12082

Kim, B. S. K., Yang, P. H., Atkinson, D. R., Wolfe, M. M., \& Hong, S. (2001). Cultural Value Similarities and Differences Among Asian American Ethnic Groups. Cultural Diversity \& Ethnic Minority Psychology, 7(4), 343-361. doi:10.1037/1099-9809.7.4.343 PMID:11759271

Krasnova, H., Veltri, N. F., \& Günther, O. (2012). Self-disclosure and Privacy Calculus on Social Networking Sites: The Role of Culture. Business \& Information Systems Engineering, 4(3), 127-135. doi:10.1007/s12599012-0216-6

Kuwabara, K., Willer, R., Macy, M. W., Mashima, R., Terai, S., \& Yamagishi, T. (2007). Culture, Identity, and Structure in Social Exchange: A Web-Based Trust Experiment in the United States and Japan. Social Psychology Quarterly, 70(4), 461-479. doi:10.1177/019027250707000412

Li, Y. (2011). Empirical Studies on Online Information Privacy Concerns: Literature Review and an Integrative Framework. Communications of the Association for Information Systems, 28(1), 453-496. doi:10.17705/1CAIS.02828

Liao, C., Liu, C., \& Chen, K. (2011). Examining the impact of privacy, trust, and risk perceptions beyond monetary transactions: An integrated model. Electronic Commerce Research and Applications, 10(6), 702-715. doi:10.1016/j.elerap.2011.07.003

Lindell, M. K., \& Whitney, D. J. (2001). Accounting for common method variance in cross-sectional research designs. The Journal of Applied Psychology, 86(1), 114-121. doi:10.1037/0021-9010.86.1.114 PMID:11302223 
Lowry, P. B., Cao, J., \& Everard, A. (2011). Privacy Concerns Versus Desire for Interpersonal Awareness in Driving the Use of Self-Disclosure Technologies: The Case of Instant Messaging in Two Cultures. Journal of Management Information Systems, 27(4), 163-200. doi:10.2753/MIS0742-1222270406

Lwin, M., Wirtz, J., \& Williams, J. D. (2007). Consumer online privacy concerns and responses: A powerresponsibility equilibrium perspective. Journal of the Academy of Marketing Science, 35(4), 572-585. doi:10.1007/s11747-006-0003-3

Mai, B., Menon, N., \& Sarkar, S. (2010). No Free Lunch: Price Premium for Privacy Seal-Bearing Vendors. Journal of Management Information Systems, 27(2), 189-212. doi:10.2753/MIS0742-1222270206

Malhotra, K. N., Kim, S. S., \& Agarwal, J. (2004). Internet users' information privacy concerns (IUIPC): The construct, the scale, and a causal model. Information Systems Research, 15(4), 336-355. doi:10.1287/ isre. 1040.0032

Mayer, R., Davis, J., \& Schoorman, F. (1995). An integrative model of organizational trust. Academy of Management Review, 20(3), 709-734. doi:10.5465/amr.1995.9508080335

Metzger, M. J. (2004). Privacy, Trust, and Disclosure: Exploring Barriers to Electronic Commerce. Journal of Computer-Mediated Communication, 9(4), 9. doi:10.1111/j.1083-6101.2004.tb00292.x

Milberg, S. J., Burke, S. J., Smith, H. J., \& Kallman, E. A. (1995). Values, personal information privacy, and regulatory approaches. Communications of the ACM, 38(12), 65-74. doi:10.1145/219663.219683

Milberg, S. J., Smith, H. J., \& Burke, S. J. (2000). Information Privacy: Corporate Management and National Regulation. Organization Science, 11(1), 35-57. doi:10.1287/orsc.11.1.35.12567

Miltgen, C. L., \& Smith, H. J. (2015). Exploring information privacy regulation, risks, trust, and behavior. Information \& Management, 52(6), 741-759. doi:10.1016/j.im.2015.06.006

Minkov, M., \& Hofstede, G. (2011). The evolution of Hofstede's doctrine. Cross Cultural Management, 18(1), 10-20. doi:10.1108/13527601111104269

Nijhawan, D. R. (2003). The emperor has no clothes: A critique of applying the European Union Approach to privacy regulation in the United States. Vanderbilt Law Review, 56(3), 939-976.

Nisbett, R. E., Peng, K., Choi, I., \& Norenzayan, A. (2001). Culture and systems of thought: Holistic versus analytic cognition. Psychological Review, 108(2), 291-310. doi:10.1037/0033-295X.108.2.291 PMID:11381831

Okazaki, S., Li, H., \& Hirose, M. (2009). Consumer Privacy Concerns and Preference for Degree of Regulatory Control. Journal of Advertising, 38(4), 63-77. doi:10.2753/JOA0091-3367380405

Paxton, P. (2007). Association Memberships and Generalized Trust: A Multilevel Model Across 31 Countries. Social Forces, 86(1), 47-76. doi:10.1353/sof.2007.0107

Poortinga, W., \& Pidgeon, N. F. (2005). Trust in Risk Regulation: Cause or Consequence of the Acceptability of GM Food? Risk Analysis, 25(1), 199-209. doi:10.1111/j.0272-4332.2005.00579.x PMID:15787769

Qian, W., Razzaque, M. A., \& Keng, K. A. (2007). Chinese cultural values and gift-giving behavior. Journal of Consumer Marketing, 24(4), 214-228. doi:10.1108/07363760710756002

Ringle, C. M., Wende, S., \& Becker, J.-M. (2015). SmartPLS 3. Hamburg, Germany: Boenningstedt: SmartPLS $\mathrm{GmbH}$.

Sharma, P. (2010). Measuring peronal cultural orientations: Scale development and validation. Journal of the Academy of Marketing Science, 38(6), 787-806. doi:10.1007/s11747-009-0184-7

Singer, N. (2013, February 2). Data protection laws, an ocean apart. The New York Times.

Smith, H. J. (1994). Managing privacy: information technology and corporate America. University of North Carolina Press.

Smith, H. J. (2001). Information Privacy and Marketing: What the U.S. Should (and Shouldn't) Learn from Europe. California Management Review, 43(2), 8-33. doi:10.2307/41166073 
Smith, H. J., Dinev, T., \& Xu, H. (2011). Information Privacy Research: An Interdisciplinary Review. Management Information Systems Quarterly, 35(4), 989-1015. doi:10.2307/41409970

Smith, H. J., Milberg, S. J., \& Burke, S. J. (1996). Information privacy: Measuring individuals' concerns about organizational practices. Management Information Systems Quarterly, 20(2), 167-196. doi:10.2307/249477

Son, J. Y., \& Kim, S. S. (2008). Internet users' information privacy-protective responses: A taxonomy and a nomological model. Management Information Systems Quarterly, 32(3), 503-529. doi:10.2307/25148854

Srite, M., \& Karahanna, E. (2006). The Role of Espoused National Cultural Values in Technology Acceptance. Management Information Systems Quarterly, 30(3), 679-704. doi:10.2307/25148745

Sterling, G. (2019). Most consumers believe online privacy is impossible, survey finds. Retrieved from https:// marketingland.com/most-consumers-believe-online-privacy-is-impossible-survey-finds-263538

Stewart, K. A., \& Segars, A. H. (2002). An Empirical Examination of the Concern for Information Privacy Instrument. Information Systems Research, 13(1), 36-49. doi:10.1287/isre.13.1.36.97

Sutanto, J., Palme, E., Tan, C.-H., \& Phang, C. W. (2013). Addressing the personalization-privacy paradox: An empirical assessment from a field experiment on smartphone users. Management Information Systems Quarterly, 37(4), 1141-1164. doi:10.25300/MISQ/2013/37.4.07

Takahashi, C., Yamagishi, T., Liu, J. H., Wang, F., Lin, Y., \& Yu, S. (2008). The intercultural trust paradigm: Studying joint cultural interaction and social exchange in real time over the Internet. International Journal of Intercultural Relations, 32(3), 215-228. doi:10.1016/j.ijintrel.2007.11.003

Tang, Z., Hu, J., \& Smith, M. D. (2008). Gaining Trust Through Online Privacy Protection: Self-Regulation, Mandatory Standards, or Caveat Emptor. Journal of Management Information Systems, 24(4), 153-173. doi:10.2753/MIS0742-1222240406

Tsai, J. Y., Egelman, S., Cranor, L., \& Acquisti, A. (2011). The Effect of Online Privacy Information on Purchasing Behavior: An Experimental Study. Information Systems Research, 22(2), 254-268. doi:10.1287/isre.1090.0260

Weber, E. U., \& Hsee, C. (1998). Cross-cultural Differences in Risk Perception, but Cross-cultural Similarities in Attitudes Towards Perceived Risk. Management Science, 44(9), 1205-1217. doi:10.1287/mnsc.44.9.1205

Westin, A. F. (2004). How to craft effective online privacy policies. Privacy and American Business, 11(6), 1-2.

Xu, H., Teo, H. H., \& Tan, B. C. Y. (2005, December). Predicting the Adoption of Location-Based Services: The Roles of Trust and Privacy Risk. Proceedings of 26th Annual International Conference on Information Systems (ICIS 2005).

Xu, H., Teo, H.-H., Tan, B. C. Y., \& Agarwal, R. (2012). Research Note-Effects of Individual Self-Protection, Industry Self-Regulation, and Government Regulation on Privacy Concerns: A Study of Location-Based Services. Information Systems Research, 23(4), 1342-1363. doi:10.1287/isre.1120.0416

Yang, H., \& Liu, H. (2014). Prior negative experience of online disclosure, privacy concerns, and regulatory support in Chinese social media. Chinese Journal of Communication, 7(4), 40-59. doi:10.1080/17544750.20 13.816756

Yoo, B., Donthu, N., \& Lenartowicz, T. (2011). Measuring Hofstede's Five Dimensions of cultural Values at the Individual Level: Development and Validation of CVSCALE. Journal of International Consumer Marketing, 23, 193-210.

\section{ENDNOTES}

Our search was conducted using several online databases of scholarly articles. We searched for articles that incorporated at least two of privacy concerns, cultural values, and regulation in the research framework, and we followed citation trails that showed which articles were citing and were being cited by others. While we cannot claim that this list is fully exhaustive, we are confident that it is largely comprehensive within the boundaries of our search algorithm. 
Antecedents, consequents, and mediators/moderators were categorized by this study's authors based on their reading of the articles listed above.

Refer to cultural dimensions that were examined in the study. Abbreviations (e.g., PDI, IND) are associated with Hoftsede (2001). The phrase "GLOBE dimensions" refers to the Global Leadership and Organizational Behavior Effectiveness (GLOBE) project (House, Javidan, Hanges, \& Dorfman, 2002).

Miltgen and Smith (2015) included a construct called "privacy risk concerns," which intermingled the two concepts. We have noted this in both columns in this table.

Additionally, as part of a post hoc exploration, Bellman et al (2004) considered the indices individually. As will be seen in the next section, a few studies have considered cross-national differences in trust, but those studies were outside the direct research domain of this study.

Although Dinev et al (2006) and Krasnova et al (2012) also included this linkage in their models, their derivation focused on cultural moderations of the relationships rather than on the linkage itself.

See https://geerthofstede.com/wp-content/uploads/2016/07/VSM-2013-English-2013-08-25.pdf and https://geerthofstede.com/wp-content/uploads/2016/07/Manual-VSM-2013.pdf.

Farrell et al. (2016) examine the quality of MTurk workers and find that they are as motivated as student participants to make costly choices. Additionally, compared with student participants, the study finds that MTurk workers exert sufficient effort in research tasks and provide honest demographic information. The median survey completion time was 10 minutes. These compensations thus equate to an hourly rate of $\$ 9$ and $\$ 7.50$ for American and Indian participants, respectively.

Entries in Table 8 represent our own interpretations of the authors' references in their figures and text. For the purposes of documenting Bélanger and Crossler (2011)'s model, we include not only the constructs that are shown in their Figure 2 but also other constructs that are referenced in their text. Bélanger and Crossler (2011) include separate constructs for "group" and "individual" privacy concerns. We have included all variables that are antecedents to either of these types.

$\mathrm{Li}$ (2011) includes separate constructs for "general," "specific," and "societal" privacy concerns. We have included all variables that are antecedents to any of these types. Adapted from Smith (2001). Bellman et al (2004) embraced a categorization with three levels: None/ self-help, sectoral, and omnibus. 


\title{
APPENDIX A
}

\author{
Table 10. Survey Items
}

Masculinity/Femininity

MF1: Solving organizational problems requires the active forcible approach, which is more typical of men than women.

MF2: It is preferable to have a man in a high-level position rather than a woman.

MF3: It is more important for men to have a professional career than it is for women.

MF4: There are some leadership positions that a man can always do better than a woman.

MF5: Money and material things are important criteria in judging professional success.

LTO - planning

LTOP1: I believe in planning for the long term rather than focusing on the short term.

LTOP2: One should work hard now for a better future. (adapted from Sharma)

LTOP3: It is important to manage money carefully to have enough later in life.

LTO - tradition

LTOT1: I am proud of my culture.

LTOT2: I care a lot about my family history. .

LTOT3: I value a strong link to my past.

LTOT4: Respect for tradition is important to me.

LTOT5: Traditional values are important to me.

Individualism/collectivism

IC1: Group success is more important than individual success.

IC2: Employees should only pursue their goals after considering the welfare of the group.

IC3: Managers should encourage group loyalty even if individual goals suffer.

IC4: Individuals may be expected to give up their goals in order to benefit group success.

IC5: Being loyal to a group is more important than individual gain.

IC6: Group welfare is more important than individual rewards.

IC7: Being accepted as a member of a group is more important than having autonomy and independence.

Power distance

PD1: Managers should make most decisions without consulting subordinates.

PD2: Managers should seldom ask for the opinions of employees.

PD3: Decision making power should stay with top management in the organization and not be delegated to lower level employees.

PD4: Managers should not ask subordinates for advice, because they might appear less powerful.

PD5: Employees should not question their manager's decisions.

Uncertainty avoidance

UA1: It is important to have job requirements and instructions spelled out in detail so that employees always know what they are expected to do.

UA2: Rules and regulations are important because they inform employees what the organization expects of them.

UA3: Standard operating procedures are helpful to employees on the job.

UA4: Order and structure are very important in a work environment

UA5: It is important for employees to closely follow instructions and procedures.

Regulatory Preferences

REG1: The existing laws in my country are sufficient to protect consumers' online privacy.

REG2 There are stringent laws to protect personal information of individuals on the Internet.

REG3: The regulation of consumers' online privacy is in safe hands with the government.

REG4: I feel confident that the government adequately regulates consumers' online privacy.

REG5: The government is doing enough to ensure that consumers are protected against online privacy violations.

REG6: I feel that the current regulations are sufficient to control the collection and use of personal information on the Internet.

Trust beliefs

TR1: Online companies in general would be trustworthy in handling my personal information.

TR2: Online companies would keep my best interests in mind when dealing with my personal information.

TR3: Online companies would fulfill their promises related to my personal information.

TR4: Online companies are in general predictable and consistent regarding the usage of my personal information.

Intention to disclose 


\section{Table 10. Continued}

ITD1: Purchase goods (e.g., books or CDs) from websites that require me to submit accurate and identifiable information (such as credit card information).

ITD2: Purchase services (e.g., airline tickets or hotel reservations) from websites that require me to submit accurate and identifiable information (such as credit card information).

ITD3: Conduct sales transactions at e-commerce sites that require me to provide credit card information (e.g., using sites for purchasing goods or software)

ITD4: Retrieve information from websites that require me to submit identifiable information (such as sites that provide personalized stock quotes, insurance rates, or loan rates).

\section{Risk beliefs}

RI1: Providing online companies with my personal information would involve many unexpected problems.

RI2: It would be risky to disclose my personal information to online companies.

RI3: There would be high potential for loss in disclosing my personal information to online companies.

RI4: There would be too much uncertainty associated with giving my personal information to online companies.

RI5: I would feel safe giving my personal information to online companies. (Reverse coded)

Collection

COL1: It usually bothers me when online companies ask me for personal information

COL2: When online companies ask me for personal information, I sometimes think twice before providing it.

COL3: I am concerned that online companies are collecting too much personal information about me.

\section{Secondary use}

SU1: I am concerned that when I give personal information to online companies for some reason, they would use the information for other reasons.

SU2: I am concerned that online companies would sell my personal information in their computer databases to other companies.

SU3; I am concerned that online companies would share my personal information with other companies without my authorization.

Errors

ERR1: I am concerned that online companies do not take enough steps to make sure that my personal information in their files is accurate. ERR2: I am concerned that online companies do not have adequate procedures to correct errors in my personal information.

ERR3: I am concerned that online companies do not devote enough time and effort to verifying the accuracy of my personal information in their databases.

\section{Improper access}

IA1: I am concerned that online companies' databases that contain my personal information are not protected from unauthorized access.

IA2: I am concerned that online companies do not devote enough time and effort to preventing unauthorized access to my personal information.

IA3: I am concerned that online companies do not take enough steps to make sure that unauthorized people cannot access my personal information in their computers.

Control

CON1: It usually bothers me when I do not have control of personal information that I provide to online companies.

CON2: It usually bothers me when I do not have control or autonomy over decisions about how my personal information is collected, used, and shared by online companies.

CON3: I am concerned when control is lost or unwillingly reduced as a result of a marketing transaction with online companies.

\section{Awareness}

AW1: I am concerned when a clear and conspicuous disclosure is not included in online privacy policies of online companies.

AW2: It usually bothers me when I am not aware or knowledgeable about how my personal information will be used by online companies.

AW3: It usually bothers me when online companies seeking my information online do not disclose the way the data are collected, processed, and used. 


\section{APPENDIX B}

Table 12. Factor Matrix for Research Model

\begin{tabular}{|c|c|c|c|c|c|c|c|c|c|c|c|c|c|c|c|c|}
\hline & IA & AW & COL & CON & ERR & SU & IC & LTOP & LTOT & MF & PD & UA & RI & TR & ITD & REG \\
\hline \multicolumn{17}{|c|}{ Improper access } \\
\hline IA1 & 0.94 & 0.56 & 0.70 & 0.71 & 0.72 & 0.80 & -0.15 & -0.08 & -0.20 & -0.15 & -0.07 & -0.15 & 0.71 & -0.50 & -0.18 & -0.41 \\
\hline IA2 & 0.93 & 0.59 & 0.69 & 0.70 & 0.76 & 0.75 & -0.08 & 0.00 & -0.20 & -0.17 & -0.12 & -0.07 & 0.72 & -0.49 & -0.20 & -0.43 \\
\hline IA3 & 0.94 & 0.62 & 0.70 & 0.70 & 0.71 & 0.77 & -0.11 & -0.06 & -0.24 & -0.19 & -0.16 & -0.13 & 0.71 & -0.56 & -0.16 & -0.44 \\
\hline \multicolumn{17}{|c|}{ Awareness } \\
\hline AW1 & 0.43 & 0.81 & 0.53 & 0.56 & 0.40 & 0.51 & 0.03 & 0.11 & 0.06 & -0.08 & 0.04 & 0.15 & 0.43 & -0.23 & -0.05 & -0.25 \\
\hline AW2 & 0.61 & 0.87 & 0.63 & 0.75 & 0.53 & 0.70 & -0.06 & -0.01 & -0.13 & -0.18 & -0.06 & 0.02 & 0.59 & -0.37 & -0.23 & -0.25 \\
\hline AW3 & 0.57 & 0.90 & 0.66 & 0.73 & 0.44 & 0.66 & -0.07 & 0.09 & -0.11 & -0.24 & -0.22 & 0.13 & 0.50 & -0.41 & -0.12 & -0.32 \\
\hline \multicolumn{17}{|c|}{ Collection } \\
\hline COL1 & 0.62 & 0.59 & 0.87 & 0.67 & 0.64 & 0.69 & -0.02 & 0.06 & -0.07 & -0.03 & 0.01 & -0.05 & 0.69 & -0.36 & -0.25 & -0.24 \\
\hline COL2 & 0.55 & 0.59 & 0.81 & 0.60 & 0.50 & 0.58 & 0.09 & 0.10 & 0.02 & -0.09 & -0.05 & -0.02 & 0.51 & -0.30 & -0.10 & -0.24 \\
\hline COL3 & 0.72 & 0.61 & 0.85 & 0.71 & 0.63 & 0.71 & -0.08 & -0.05 & -0.13 & -0.17 & -0.13 & -0.10 & 0.65 & -0.46 & -0.20 & -0.35 \\
\hline \multicolumn{17}{|c|}{ Control } \\
\hline CON1 & 0.63 & 0.69 & 0.71 & 0.89 & 0.59 & 0.73 & -0.09 & 0.06 & -0.09 & -0.15 & -0.07 & 0.10 & 0.62 & -0.40 & -0.12 & -0.28 \\
\hline CON2 & 0.67 & 0.73 & 0.72 & 0.87 & 0.60 & 0.72 & -0.16 & -0.03 & -0.15 & -0.23 & -0.11 & -0.08 & 0.63 & -0.47 & -0.17 & -0.35 \\
\hline CON3 & 0.66 & 0.66 & 0.62 & 0.85 & 0.58 & 0.64 & -0.13 & -0.01 & -0.16 & -0.13 & -0.03 & -0.02 & 0.56 & -0.40 & -0.18 & -0.35 \\
\hline \multicolumn{17}{|c|}{ Errors } \\
\hline ERR1 & 0.74 & 0.48 & 0.65 & 0.62 & 0.91 & 0.66 & -0.04 & -0.06 & -0.05 & 0.01 & 0.06 & -0.12 & 0.65 & -0.33 & -0.24 & -0.21 \\
\hline ERR2 & 0.68 & 0.48 & 0.63 & 0.60 & 0.90 & 0.62 & -0.06 & 0.04 & -0.07 & -0.11 & 0.09 & -0.17 & 0.60 & -0.33 & -0.22 & -0.31 \\
\hline ERR3 & 0.67 & 0.47 & 0.60 & 0.59 & 0.87 & 0.62 & -0.02 & 0.04 & -0.03 & -0.08 & 0.02 & -0.09 & 0.58 & -0.31 & -0.09 & -0.29 \\
\hline \multicolumn{17}{|c|}{ Secondary use } \\
\hline SU1 & 0.77 & 0.68 & 0.77 & 0.73 & 0.70 & 0.87 & -0.06 & 0.01 & -0.06 & -0.07 & -0.02 & 0.01 & 0.73 & -0.41 & -0.16 & -0.32 \\
\hline SU2 & 0.67 & 0.58 & 0.64 & 0.67 & 0.60 & 0.87 & -0.13 & -0.13 & -0.21 & -0.21 & -0.08 & -0.09 & 0.62 & -0.46 & -0.14 & -0.34 \\
\hline SU3 & 0.74 & 0.65 & 0.65 & 0.70 & 0.56 & 0.89 & -0.10 & -0.03 & -0.20 & -0.28 & -0.16 & -0.08 & 0.66 & -0.54 & -0.13 & -0.37 \\
\hline \multicolumn{17}{|c|}{ Individualism/collectivism } \\
\hline IC1 & -0.12 & -0.06 & -0.03 & -0.13 & -0.05 & -0.11 & 0.83 & 0.12 & 0.44 & 0.24 & 0.18 & 0.18 & 0.01 & 0.34 & -0.08 & 0.30 \\
\hline IC2 & 0.03 & 0.07 & 0.08 & -0.01 & 0.06 & 0.00 & 0.79 & 0.21 & 0.40 & 0.22 & 0.12 & 0.22 & 0.03 & 0.26 & -0.02 & 0.25 \\
\hline IC3 & -0.09 & -0.10 & 0.02 & -0.18 & -0.07 & -0.10 & 0.72 & 0.20 & 0.47 & 0.33 & 0.28 & 0.17 & 0.02 & 0.31 & 0.06 & 0.34 \\
\hline IC4 & -0.06 & -0.01 & -0.01 & -0.08 & -0.05 & -0.05 & 0.70 & 0.19 & 0.37 & 0.25 & 0.18 & 0.19 & -0.01 & 0.26 & 0.07 & 0.30 \\
\hline IC5 & -0.15 & -0.01 & -0.01 & -0.10 & -0.05 & -0.10 & 0.90 & 0.26 & 0.58 & 0.33 & 0.24 & 0.23 & -0.08 & 0.43 & 0.01 & 0.38 \\
\hline IC6 & -0.10 & 0.02 & 0.05 & -0.11 & -0.02 & -0.05 & 0.89 & 0.21 & 0.49 & 0.20 & 0.15 & 0.11 & -0.04 & 0.31 & -0.04 & 0.30 \\
\hline IC7 & -0.17 & -0.13 & -0.13 & -0.19 & -0.05 & -0.17 & 0.76 & 0.20 & 0.47 & 0.36 & 0.18 & 0.23 & -0.08 & 0.34 & -0.10 & 0.34 \\
\hline \multicolumn{17}{|c|}{ Long term orientation-planning } \\
\hline LTOP1 & 0.01 & 0.11 & 0.10 & 0.04 & 0.11 & 0.04 & 0.14 & 0.75 & 0.26 & 0.14 & 0.07 & 0.21 & 0.02 & 0.08 & -0.01 & 0.09 \\
\hline LTOP2 & -0.11 & -0.03 & -0.04 & -0.07 & -0.05 & -0.13 & 0.31 & 0.89 & 0.39 & 0.21 & 0.16 & 0.37 & -0.08 & 0.23 & 0.17 & 0.17 \\
\hline LTOP3 & 0.03 & 0.15 & 0.10 & 0.10 & 0.01 & 0.01 & 0.07 & 0.72 & 0.25 & 0.11 & 0.06 & 0.39 & 0.02 & 0.02 & 0.11 & 0.00 \\
\hline \multicolumn{17}{|c|}{ Long term orientation -tradition } \\
\hline LTOT1 & -0.30 & -0.13 & -0.13 & -0.15 & -0.12 & -0.24 & 0.47 & 0.32 & 0.83 & 0.33 & 0.36 & 0.34 & -0.15 & 0.52 & 0.11 & 0.48 \\
\hline LTOT2 & -0.05 & 0.07 & 0.09 & 0.01 & 0.08 & 0.00 & 0.41 & 0.33 & 0.80 & 0.19 & 0.18 & 0.24 & 0.00 & 0.26 & 0.09 & 0.33 \\
\hline LTOT3 & -0.08 & 0.09 & 0.06 & -0.03 & 0.03 & 0.00 & 0.40 & 0.36 & 0.77 & 0.24 & 0.24 & 0.24 & -0.02 & 0.30 & 0.14 & 0.29 \\
\hline LTOT4 & -0.24 & -0.16 & -0.15 & -0.22 & -0.09 & -0.23 & 0.56 & 0.33 & 0.90 & 0.45 & 0.34 & 0.31 & -0.18 & 0.53 & 0.13 & 0.41 \\
\hline LTOT5 & -0.24 & -0.13 & -0.12 & -0.19 & -0.10 & -0.20 & 0.56 & 0.32 & 0.89 & 0.49 & 0.40 & 0.38 & -0.15 & 0.55 & 0.15 & 0.42 \\
\hline \multicolumn{17}{|c|}{ Masculinity/femininity } \\
\hline MF1 & -0.13 & -0.19 & -0.05 & -0.19 & 0.03 & -0.15 & 0.35 & 0.18 & 0.41 & 0.87 & 0.53 & 0.12 & -0.03 & 0.39 & 0.07 & 0.34 \\
\hline MF2 & -0.08 & -0.17 & -0.05 & -0.15 & -0.05 & -0.11 & 0.24 & 0.16 & 0.28 & 0.85 & 0.42 & 0.12 & 0.01 & 0.28 & 0.07 & 0.25 \\
\hline MF3 & -0.18 & -0.21 & -0.13 & -0.17 & -0.07 & -0.21 & 0.35 & 0.13 & 0.37 & 0.87 & 0.52 & 0.08 & -0.12 & 0.49 & 0.06 & 0.40 \\
\hline MF4 & -0.17 & -0.20 & -0.12 & -0.20 & -0.08 & -0.23 & 0.30 & 0.20 & 0.40 & 0.91 & 0.42 & 0.21 & -0.09 & 0.42 & 0.10 & 0.30 \\
\hline
\end{tabular}


Table 12. Continued

\begin{tabular}{|c|c|c|c|c|c|c|c|c|c|c|c|c|c|c|c|c|}
\hline & IA & AW & COL & CON & ERR & SU & IC & LTOP & LTOT & MF & PD & UA & RI & TR & ITD & REG \\
\hline MF5 & -0.20 & -0.07 & -0.14 & -0.13 & -0.10 & -0.18 & 0.20 & 0.19 & 0.34 & 0.72 & 0.43 & 0.24 & -0.14 & 0.46 & 0.14 & 0.36 \\
\hline \multicolumn{17}{|c|}{ Power distance } \\
\hline PD1 & -0.05 & -0.12 & -0.07 & -0.06 & 0.06 & -0.09 & -0.07 & -0.02 & 0.11 & 0.32 & 0.72 & -0.03 & -0.10 & 0.21 & 0.07 & 0.18 \\
\hline PD2 & -0.07 & -0.10 & 0.00 & -0.06 & 0.14 & -0.05 & 0.28 & 0.04 & 0.33 & 0.45 & 0.74 & 0.01 & -0.06 & 0.42 & 0.07 & 0.33 \\
\hline PD3 & -0.14 & 0.01 & -0.08 & -0.05 & -0.04 & -0.08 & 0.26 & 0.21 & 0.37 & 0.44 & 0.80 & 0.33 & -0.07 & 0.43 & 0.10 & 0.30 \\
\hline PD4 & -0.04 & -0.19 & -0.05 & -0.08 & 0.11 & -0.05 & 0.10 & 0.02 & 0.23 & 0.50 & 0.79 & -0.01 & -0.01 & 0.31 & 0.09 & 0.24 \\
\hline PD5 & -0.17 & -0.05 & -0.06 & -0.06 & -0.01 & -0.11 & 0.20 & 0.19 & 0.27 & 0.35 & 0.77 & 0.30 & -0.12 & 0.31 & 0.02 & 0.31 \\
\hline \multicolumn{17}{|c|}{ Uncertainty avoidance } \\
\hline UA1 & -0.12 & 0.04 & -0.06 & -0.01 & -0.13 & -0.05 & 0.16 & 0.19 & 0.13 & 0.04 & 0.06 & 0.70 & -0.04 & 0.07 & -0.01 & 0.17 \\
\hline UA2 & -0.09 & 0.17 & -0.01 & 0.06 & -0.09 & 0.00 & 0.18 & 0.28 & 0.22 & 0.10 & 0.08 & 0.82 & 0.00 & 0.09 & 0.05 & 0.13 \\
\hline UA3 & -0.09 & 0.12 & -0.03 & -0.01 & -0.10 & -0.02 & 0.11 & 0.33 & 0.20 & 0.04 & -0.01 & 0.71 & -0.09 & 0.04 & 0.07 & 0.07 \\
\hline UA4 & -0.05 & 0.07 & -0.06 & 0.04 & -0.08 & -0.03 & 0.16 & 0.34 & 0.33 & 0.19 & 0.22 & 0.79 & 0.01 & 0.18 & 0.01 & 0.18 \\
\hline UA5 & -0.14 & 0.06 & -0.08 & -0.06 & -0.14 & -0.11 & 0.27 & 0.41 & 0.42 & 0.22 & 0.26 & 0.87 & -0.11 & 0.27 & 0.09 & 0.29 \\
\hline \multicolumn{17}{|c|}{ Risk beliefs } \\
\hline RI1 & 0.57 & 0.43 & 0.59 & 0.48 & 0.50 & 0.55 & 0.17 & 0.02 & 0.07 & 0.10 & 0.05 & -0.04 & 0.73 & -0.25 & -0.15 & -0.18 \\
\hline RI2 & 0.67 & 0.55 & 0.68 & 0.67 & 0.61 & 0.71 & 0.02 & 0.03 & -0.05 & -0.07 & -0.05 & -0.01 & 0.88 & -0.40 & -0.15 & -0.30 \\
\hline RI3 & 0.57 & 0.42 & 0.57 & 0.46 & 0.55 & 0.53 & 0.01 & -0.05 & -0.04 & -0.05 & -0.04 & 0.01 & 0.79 & -0.38 & -0.28 & -0.25 \\
\hline RI4 & 0.66 & 0.52 & 0.65 & 0.61 & 0.61 & 0.69 & -0.03 & -0.06 & -0.12 & -0.04 & -0.05 & -0.11 & 0.89 & -0.47 & -0.25 & -0.26 \\
\hline RI5 & 0.64 & 0.50 & 0.55 & 0.58 & 0.52 & 0.63 & -0.21 & -0.07 & -0.31 & -0.24 & -0.23 & -0.07 & 0.81 & -0.71 & -0.35 & -0.57 \\
\hline \multicolumn{17}{|c|}{ Trust beliefs } \\
\hline TR1 & -0.49 & -0.36 & -0.42 & -0.46 & -0.35 & -0.47 & 0.35 & 0.17 & 0.47 & 0.46 & 0.46 & 0.23 & -0.51 & 0.87 & 0.33 & 0.65 \\
\hline TR2 & -0.40 & -0.33 & -0.30 & -0.35 & -0.22 & -0.40 & 0.41 & 0.08 & 0.47 & 0.41 & 0.31 & 0.12 & -0.37 & 0.82 & 0.16 & 0.59 \\
\hline TR3 & -0.49 & -0.35 & -0.40 & -0.44 & -0.33 & -0.50 & 0.35 & 0.19 & 0.47 & 0.45 & 0.42 & 0.16 & -0.53 & 0.89 & 0.30 & 0.58 \\
\hline TR4 & -0.53 & -0.34 & -0.42 & -0.44 & -0.34 & -0.47 & 0.31 & 0.11 & 0.43 & 0.35 & 0.39 & 0.15 & -0.52 & 0.88 & 0.33 & 0.58 \\
\hline \multicolumn{17}{|c|}{ Intention to disclose } \\
\hline ITD1 & -0.12 & -0.10 & -0.20 & -0.14 & -0.23 & -0.14 & -0.17 & 0.05 & -0.06 & -0.14 & -0.13 & 0.04 & -0.30 & 0.10 & 0.66 & 0.02 \\
\hline ITD2 & -0.15 & -0.10 & -0.07 & -0.05 & -0.09 & -0.05 & -0.02 & 0.06 & 0.13 & 0.03 & 0.01 & 0.06 & -0.16 & 0.14 & 0.74 & 0.07 \\
\hline ITD3 & -0.20 & -0.16 & -0.25 & -0.20 & -0.26 & -0.23 & -0.09 & -0.01 & -0.03 & 0.08 & 0.00 & -0.05 & -0.32 & 0.24 & 0.79 & 0.07 \\
\hline ITD4 & -0.13 & -0.13 & -0.16 & -0.15 & -0.11 & -0.10 & 0.08 & 0.21 & 0.27 & 0.16 & 0.20 & 0.11 & -0.18 & 0.36 & 0.85 & 0.25 \\
\hline \multicolumn{17}{|c|}{ Regulatory preferences } \\
\hline REG1 & -0.39 & -0.25 & -0.28 & -0.35 & -0.22 & -0.32 & 0.35 & 0.16 & 0.43 & 0.29 & 0.29 & 0.24 & -0.38 & 0.60 & 0.07 & 0.88 \\
\hline REG2 & -0.40 & -0.29 & -0.31 & -0.35 & -0.24 & -0.38 & 0.36 & 0.13 & 0.42 & 0.33 & 0.35 & 0.23 & -0.37 & 0.60 & 0.11 & 0.88 \\
\hline REG3 & -0.38 & -0.28 & -0.31 & -0.32 & -0.26 & -0.32 & 0.37 & 0.12 & 0.38 & 0.35 & 0.33 & 0.18 & -0.32 & 0.63 & 0.22 & 0.86 \\
\hline REG4 & -0.40 & -0.32 & -0.31 & -0.34 & -0.28 & -0.36 & 0.34 & 0.10 & 0.43 & 0.41 & 0.38 & 0.20 & -0.33 & 0.64 & 0.19 & 0.92 \\
\hline REG5 & -0.41 & -0.24 & -0.26 & -0.28 & -0.29 & -0.34 & 0.37 & 0.09 & 0.42 & 0.35 & 0.30 & 0.23 & -0.33 & 0.61 & 0.23 & 0.91 \\
\hline REG6 & -0.44 & -0.31 & -0.32 & -0.37 & -0.32 & -0.39 & 0.35 & 0.11 & 0.40 & 0.35 & 0.32 & 0.18 & -0.39 & 0.63 & 0.13 & 0.90 \\
\hline
\end{tabular}

John "Skip" Benamati is a Professor of Information Systems and Chair of the Information Systems and Analytics Department at the Farmer School of Business, Miami University, Oxford, Ohio, USA. His major research and teaching interests are e-commerce trust, changing IT, information privacy, cultural differences, and IT management/strategy.

Zafer D. Ozdemir is a Professor at the Farmer School of Business, Miami University. His research focuses on economics of e-commerce and has appeared in scholarly journals such as Information Systems Research, Journal of MIS, Decision Sciences, Decision Support Systems, Information \& Management, and Communications of the ACM, among others.

H. Jeff Smith was the George and Mildred Panuska Professor in Business in the Farmer School of Business at Miami University in Oxford, Ohio. His research focused on ethical, societal, and regulatory issues associated with strategic uses of information technology. His research appeared in many highly ranked journals. 